\title{
Transmembrane AMPAR Regulatory Protein $\gamma$-2 Is Required for the Modulation of GABA Release by Presynaptic AMPARs
}

\author{
Mark Rigby, Stuart G. Cull-Candy, and Mark Farrant \\ Department of Neuroscience Physiology and Pharmacology, University College London, London WC1E 6BT, United Kingdom
}

\begin{abstract}
Presynaptic ionotropic glutamate receptors (iGluRs) play important roles in the control of synaptogenesis and neurotransmitter release, yet their regulation is poorly understood. In particular, the contribution of transmembrane auxiliary proteins, which profoundly shape the trafficking and gating of somatodendritic iGluRs, is unknown. Here we examined the influence of transmembrane AMPAR regulatory proteins (TARPs) on presynaptic AMPARs in cerebellar molecular layer interneurons (MLIs). 6-cyano-7-nitroquinoxaline-2,3-dione (CNQX), a partial agonist at TARP-associated AMPARs, enhanced spontaneous GABA release in wild-type mice but not in stargazer mice that lack the prototypical TARP stargazin $(\gamma-2)$. These findings were replicated in mechanically dissociated Purkinje cells with functional adherent synaptic boutons, demonstrating the presynaptic locus of modulation. In dissociated Purkinje cells from stargazer mice, AMPA was able to enhance mIPSC frequency, but only in the presence of the positive allosteric modulator cyclothiazide. Thus, ordinarily, presynaptic AMPARs are unable to enhance spontaneous release without $\gamma-2$, which is required predominantly for its effects on channel gating. Presynaptic AMPARs are known to reduce action potential-driven GABA release from MLIs. Although a G-protein-dependent non-ionotropic mechanism has been suggested to underlie this inhibition, paradoxically we found that $\gamma$-2, and thus AMPAR gating, was required. Following glutamate spillover from climbing fibers or application of $\mathrm{CNQX}$, evoked GABA release was reduced; in stargazer mice such effects were markedly attenuated in acute slices and abolished in the dissociated Purkinje cell-nerve bouton preparation. We suggest that $\gamma-2$ association, by increasing charge transfer, allows presynaptic AMPARs to depolarize the bouton membrane sufficiently to modulate both phasic and spontaneous release.
\end{abstract}

Key words: AMPA receptor; cerebellum; glutamate; IPSC; molecular layer interneurons; neurotransmitter release

\section{Introduction}

Presynaptic ionotropic glutamate receptors (iGluRs) modify neurotransmitter release (Bureau and Mulle, 1998; Pinheiro and Mulle, 2008; Contractor et al., 2011), growth cone motility (Chang and De Camilli, 2001; Tashiro et al., 2003; Wang et al., 2011), the distribution of synaptic vesicles (Schenk et al., 2005), and axonal excitability (Semyanov and Kullmann, 2001; Sasaki et al., 2011). Despite the recognized importance of these presynaptic receptors in synapse formation and function, little is known about their subcellular trafficking and regulation. Specifically, at the nerve

Received Oct. 2, 2014; revised Jan. 10, 2015; accepted Jan. $28,2015$.

Author contributions: M.R., S.G.C.-C. and M.F. designed research; M.R. performed research; M.R. and M.F. analyzed data; M.R., S.G.C.-C., and M.F. wrote the paper.

This work was supported by the Wellcome Trust (086185/Z/08/Z to S.G.C.-C. and M.F.) and the Medical Research Council, United Kingdom (MR/J002976/1 to S.G.C.-C. and M.F.; MR/J012998/1 to M.F. and S.G.C.-C.). M.R. received a Wellcome Trust Studentship. We thank Guy Moss, David Benton, and Alan Robertson for advice on vibrodissociation; Tomoyuki Takahashi for comments on an earlier version of the manuscript; and Cécile Bats and Steve Sullivan for valuable discussions.

The authors declare no competing financial interests.

This article is freely available online through the J Neurosci Author Open Choice option.

Correspondence should be addressed to either Mark Rigby or Mark Farrant. E-mail: mark.rigby@kcl.ac.uk or m.farrant@ucl.ac.uk.

M. Rigby's present address: MRC Centre for Developmental Neurobiology, King's College London, London SE1 1UL, UK.

DOI:10.1523/JNEUROSCI.4075-14.2015

Copyright $\odot 2015$ Rigby et al.

This is an Open Access article distributed under the terms of the Creative Commons Attribution License Creative Commons Attribution 4.0 International, which permits unrestricted use, distribution and reproduction in any medium provided that the original work is properly attributed. terminal the role of various transmembrane auxiliary subunits, which have been shown to influence profoundly the behavior of iGluRs in the somatodendritic compartment, remains unclear.

Multiple iGluR auxiliary subunits have been identified. These include, for kainate and NMDA receptors, NETO1 and NETO2 (Ng et al., 2009; Zhang et al., 2009), and for AMPARs, transmembrane AMPAR regulatory proteins (TARPs; Chen et al., 2000; Tomita et al., 2003), cornichons (Schwenk et al., 2009), CKAMP44 (von Engelhardt et al., 2010), and GSG1L (Schwenk et al., 2012; Shanks et al., 2012). Of these, the best characterized are the TARPs, which stably associate with homomeric or heteromeric assemblies of the core pore-forming GluA1-GluA4 AMPAR subunits. Thus, six TARP isoforms, $\gamma-2$ (stargazin), $\gamma-3, \gamma-4, \gamma-5$, $\gamma-7$, and $\gamma-8$, with distinct though partially overlapping patterns of expression in the CNS (Fukaya et al., 2005), have been shown to differentially modulate trafficking, synaptic targeting, gating, and pharmacology of AMPARs (Jackson and Nicoll, 2011; Straub and Tomita, 2012).

The regulation of somatodendritic AMPARs by TARPs can vary according to both the subcellular location of the receptors and their subunit composition. For example, in cerebellar molecular layer interneurons (MLIs), $\gamma$-2 normally associates with postsynaptic and extrasynaptic AMPARs. In its absence, GluA2-lacking calcium-permeable AMPARs (CP-AMPARs) but not GluA2containing calcium-impermeable AMPARs (CI-AMPARs) function at the synapse without a TARP. By contrast, extrasynaptic 
AMPARs remain functional through association with the other TARP expressed by MLIs, $\gamma-7$ (Bats et al., 2012). In cerebellar granule cells, which also contain both $\gamma-2$ and $\gamma-7$, the latter selectively inhibits CI-AMPARs from reaching the synapse and promotes the synaptic delivery of CP-AMPARs (Studniarczyk et al., 2013). Given this divergence in regulation among somatodendritic AMPARs, it seemed possible that presynaptic AMPARs might exhibit yet greater differences in regulation.

To determine whether TARPs regulate presynaptic AMPARs, we used electrophysiological measures to examine AMPAR-mediated modulation of GABA release from cerebellar MLIs (Bureau and Mulle, 1998; Satake et al., 2000). At these axonal varicosities AMPARs enhance spontaneous release by increasing voltage-gated calcium channel (VGCC) openings (Bureau and Mulle, 1998; Rossi et al., 2008) yet inhibit evoked release, potentially through a G-protein-based mechanism (Satake et al., 2000, 2004; Rusakov et al., 2005). We found that, regardless of the presynaptic AMPAR subtype, TARP $\gamma$-2 was required for AMPAR-mediated enhancement of spontaneous release and reduction of action potentialevoked release. This dependence appeared to result not from an influence of $\gamma-2$ on AMPAR trafficking, but from the increased channel gating conferred by $\gamma-2$ association.

\section{Materials and Methods}

Animals and slice preparation. Stargazer ( $\mathrm{stg} / \mathrm{stg}$ ) mice were bred from $+/$ stg mice (C57BL/6 background) and identified according to phenotype (smaller size, head tossing, unsteady gait). In each case, identification was confirmed by genotyping of tail samples (Letts et al., 1998). The primers used were as follows: ETn-OR, 5' -GCCTTGATCAGAGTAACTGTC-3'; 109F, 5' -CATTTCCTGTCTCATCCTTTG-3'; JS167, 5' -GAGCAAGCAGGTTTCAGGC-3'; and E/Ht7, 5' -ACTGTCACTCTATCTG GAATC-3'. Age-matched C57BL/6 wild-type mice were used as controls. All procedures for the care and treatment of mice were in accordance with the Animals (Scientific Procedures) Act 1986. Sagittal slices (250 $\mu \mathrm{m}$ thick) were cut from the cerebellar vermis of postnatal day (P) $10-$ P14 or P20-P24 mice of either sex, using a vibrating microslicer (650 V; $\mathrm{HM}$, Micron International). Mice were decapitated, and the brains removed and placed into ice-cold slicing solution, which contained the following (in mM): $85 \mathrm{NaCl}, 2.5 \mathrm{KCl}, 0.5 \mathrm{CaCl}_{2}, 4 \mathrm{MgCl}_{2}, 1.25 \mathrm{NaH}_{2} \mathrm{PO}_{4}$, $25 \mathrm{NaHCO}_{3}, 25$ glucose, and 64 sucrose, $\mathrm{pH} 7.4$ when bubbled with $95 \%$ $\mathrm{O}_{2}$ and $5 \% \mathrm{CO}_{2}$. Slices were transferred to a chamber containing the following extracellular solution (in mM): $125 \mathrm{NaCl}, 2.5 \mathrm{KCl}, 2 \mathrm{CaCl}_{2}, 1$ $\mathrm{MgCl}_{2}, 25 \mathrm{NaHCO}_{3}, 1.25 \mathrm{NaH}_{2} \mathrm{PO}_{4}$ and 25 glucose (bubbled with $95 \%$ $\mathrm{O}_{2}$ and $5 \% \mathrm{CO}_{2}$ ). Slices were then incubated at $34^{\circ} \mathrm{C}$ for $1 \mathrm{~h}$ before recording.

Mechanical dissociation of Purkinje cells. Purkinje cells were dissociated from $400 \mu \mathrm{m}$ sagittal cerebellar slices (prepared as above) using acute vibrodissociation in the absence of enzyme treatment (Vorobjev, 1991; Akaike and Moorhouse, 2003; Duguid et al., 2007). Slices were placed in a $35 \mathrm{~mm}$ culture dish (Nunc) on the stage of a BX51 WI upright microscope (Olympus) and viewed with a $4 \times$ objective using oblique infrared illumination. A fire-polished glass pipette was mounted in a holder connected to a speaker cone and placed over the Purkinje cell layer. Horizontal vibration was achieved by driving the speaker with a $4 \mathrm{~V}, 6 \mathrm{~ms}$ square pulse delivered at 90 $\mathrm{Hz}$ (S48 stimulator, Natus Neurology). The glass pipette was first vibrated in an elliptical pattern at the slice surface before being driven through the slice. The dissociation was performed in a solution containing the following (in $\mathrm{mm}$ ): $145 \mathrm{NaCl}, 2.5 \mathrm{KCl}, 1 \mathrm{CaCl}_{2}, 1 \mathrm{MgCl}_{2}, 10$ glucose, and 10 HEPES, pH 7.3 with $\mathrm{NaOH}$. Dissociated cells were allowed to adhere to the bottom of the dish for $10 \mathrm{~min}$ before recording.

Electrophysiology. During recording, slices or dissociated cells were continuously perfused in oxygenated extracellular solution. In all experiments, $20 \mu \mathrm{M}$ D-2-amino-5-phosphonopentanoic acid (AP5) and $10 \mu \mathrm{M}$ CGP55845 were added to block NMDA and $\mathrm{GABA}_{\mathrm{B}}$ receptors respectively. Other drugs used were $20 \mu \mathrm{M}$ 2-(3-carboxypropyl)-3-amino-6-(4 methoxyphenyl)pyridazinium bromide (SR 95531); $1 \mu \mathrm{M}$ tetrodotoxin (TTX); 2, 20, or $40 \mu \mathrm{M}$ 6-cyano-7-nitroqui- noxaline-2,3-dione (CNQX); $20 \mu \mathrm{M}$ 2,3-dihydroxy-6-nitro-7-sulfamoyl-benzo[f] quinoxaline-2,3-dione (NBQX); $2 \mu \mathrm{M}$ AMPA; and $50 \mu \mathrm{M}$ cyclothiazide. One millimole philanthotoxin-74 was included in the pipette solution in experiments where it was necessary to reduce the whole-cell AMPAR-mediated current. All drugs were from Ascent or Sigma-Aldrich.

Whole-cell patch-clamp recordings were made from the soma of either MLIs or Purkinje cells. Cells were visually identified (BX51 WI with $40 \times$ immersion objective, Olympus) using infrared oblique illumination. Recordings were obtained at room temperature $\left(22-25^{\circ} \mathrm{C}\right)$ with a Multiclamp 700B patch-clamp amplifier (Molecular Devices). Recordings were filtered at $3 \mathrm{kHz}$ (eight-pole low-pass digital Bessel) and digitized at $10 \mathrm{kHz}$ using a Digidata $1440 \mathrm{~A}$ interface and pClamp 10 software (Molecular Devices). For MLIs, patch pipettes were made from thickwalled borosilicate glass (GC-150F; Clark Electromedical) and fire polished to a resistance of 5-10 M $\Omega$. For Purkinje cells, patch pipettes were made from thin-walled borosilicate glass (G150TF-3, Warner Instruments) and fire polished to a resistance of 3.5-6 $\mathrm{M} \Omega$. All patch pipettes were coated with Sylgard resin (Dow Corning 184).

For most voltage-clamp recordings, the internal solution contained the following (in mM): $128 \mathrm{CsCl}, 10 \mathrm{HEPES}, 10 \mathrm{EGTA}, 10 \mathrm{TEACl}, 2$ $\mathrm{MgATP}, 1 \mathrm{CaCl}_{2}$, and $2 \mathrm{NaCl}$, pH 7.4 with $\mathrm{CsOH}$ (final osmolarity, $285 \pm$ $5 \mathrm{mOsmol} / \mathrm{L}$ ) and the holding potential was set at $-70 \mathrm{mV}$. For Purkinje cell recordings involving climbing fiber stimulation, the internal solution contained the following (in mM): $150 \mathrm{~K}$-gluconate, $10 \mathrm{HEPES}, 1$ EGTA, 4 MgATP, $0.1 \mathrm{CaCl}_{2}, 4.6 \mathrm{MgCl}_{2}$, and $0.4 \mathrm{NaATP}$, pH 7.4 with $\mathrm{KOH}$ (final osmolarity, $285 \pm 5 \mathrm{mOsmol} / \mathrm{L}$ ). The cells were held at $-30 \mathrm{mV}$. The same internal solution was used for current-clamp recordings of MLIs.

Series resistance, input capacitance, and input resistance were monitored at regular intervals by measuring the current transient elicited by a $10 \mathrm{mV}$ hyperpolarizing voltage step. The series resistance remaining after $60-85 \%$ compensation was typically $5-20 \mathrm{M} \Omega$; recordings were rejected if the series resistance increased above $30 \mathrm{M} \Omega$ or altered by $>30 \%$. IPSCs were evoked using a patch electrode (3-5 M $\Omega$ ) filled with external solution and placed in the molecular layer. Stimuli consisted of paired pulses (10-40 V; $20 \mu$ s duration) separated by $30 \mathrm{~ms}$. In recordings from mechanically dissociated Purkinje cells, IPSCs were evoked by directly stimulating adherent presynaptic boutons using a patch electrode $(4-6 \mathrm{M} \Omega)$ filled with external solution. Current pulses (50-100 $\mu \mathrm{A}, 1.3 \mathrm{~ms}$ ) were applied with an iontophoretic amplifier (MVCS-C Iontophoresis system, NPI Electronic).

Data analysis. Data were analyzed using Igor Pro 6.10 (Wavemetrics). mIPSCs were detected using a scaled template algorithm (Clements and Bekkers, 1997) within NeuroMatic 2.6 (http://www.neuromatic. thinkrandom.com/). The template was based on rising and decaying exponentials with time constants that were typically set at 1 and $3 \mathrm{~ms}$, respectively. The "phasic charge transfer" during each recording in TTX was calculated using an automated procedure (written in Igor Pro). For each epoch (typically $4 \mathrm{~s}$ ), an all-point amplitude histogram was generated and fit with a single-sided Gaussian to the most-positive current values, providing an estimate of the baseline current noise. The peak of the histogram was taken as the baseline current value. The integral of the section of histogram not fitted by the Gaussian represents the charge carried by the phasic synaptic events. The total charge was divided by the recording time to give a measure of phasic charge transfer per second. Unlike measurement of mIPSC frequency, this approach involved no subjective assignment of parameters for the template or subjective selection of the synaptic events themselves. Although the measure includes mIPSCs and mEPSCs, the much lower frequency and charge of the latter means that their contribution was negligible. mIPSCs were segregated on the basis of their amplitudes and rise times using Divisive Analysis Clustering in R 2.15.1 (R Foundation for Statistical Computing; http://www.r-project.org/) and RStudio 0.96.331 (RStudio).

For evoked IPSCs, the paired-pulse ratio (PPR) was determined by dividing the amplitude of the second IPSC by that of the first. Amplitudes and PPR values were determined from individual sweeps before numerical averaging. The coefficient of variation $(\mathrm{CV})$ of the amplitude of the first evoked IPSC was calculated as the SD/mean.

Statistics. All data are expressed as mean \pm SEM. The $n$ number indicates the number of cells. Differences between groups were examined 
A

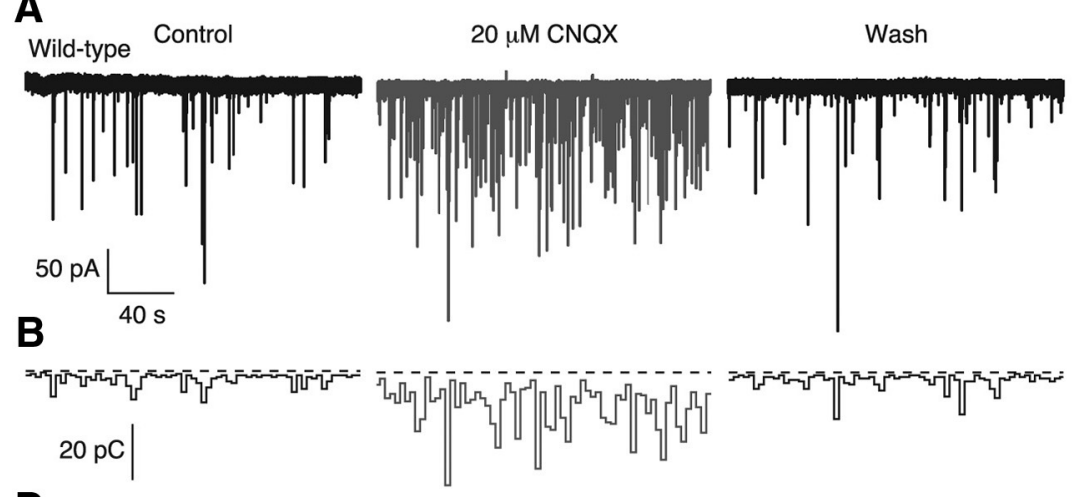

D

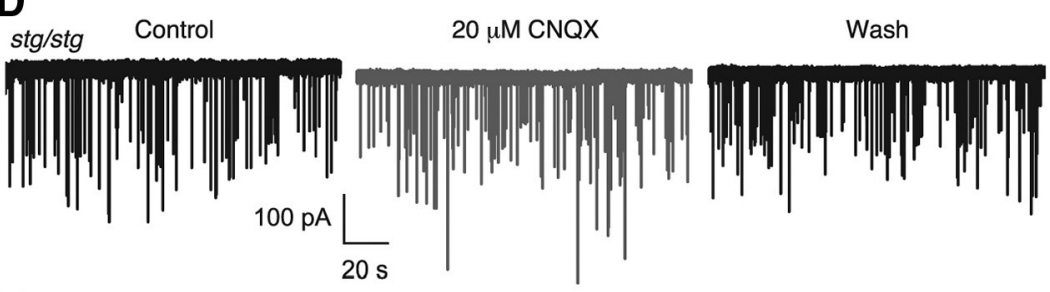

$\mathbf{E}$

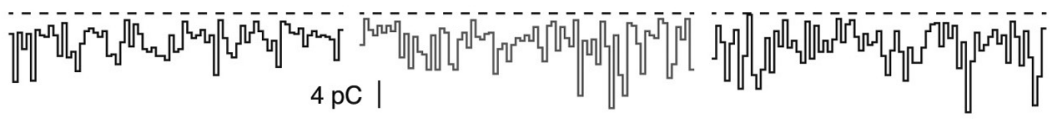

G

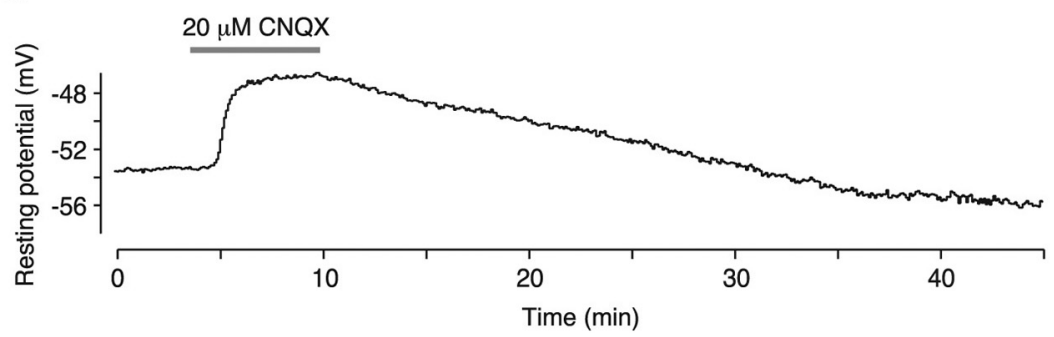

C

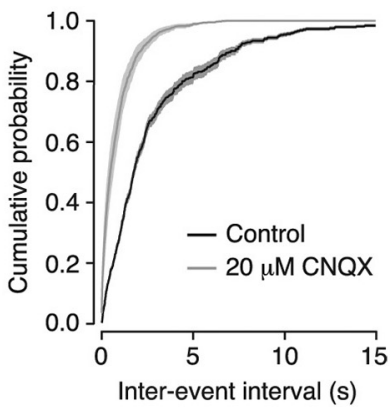

$\mathbf{F}$

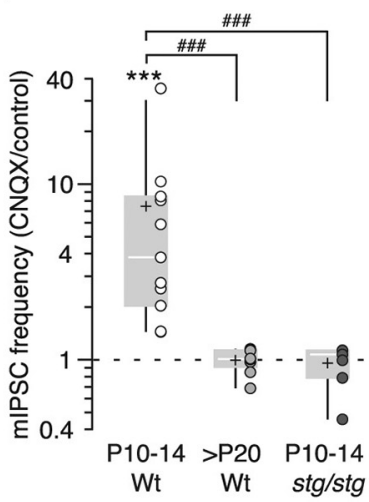

H

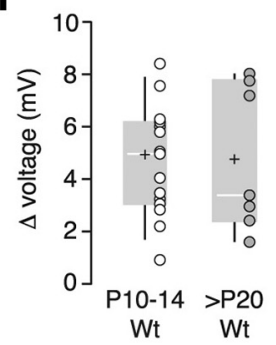

Figure 1. CNQX increases mIPSC frequency in wild-type P10-P14 MLIs. $\boldsymbol{A}, \boldsymbol{B}$, Representative current records $(\boldsymbol{A})$ and phasic charge transfer measurements $(\boldsymbol{B})$ from a MLI in a slice from a P10 wild-type mouse (dashed lines indicate 0 ). C, Averaged cumulative probability histograms of mIPSC inter-event intervals. Lines and shaded regions represent the averages and SEMs, respectively $(n=11) . \boldsymbol{D}, \boldsymbol{E}$, Records from a P12 stg/stg MLl as described for $\boldsymbol{A}$ and $\boldsymbol{B}$. $\boldsymbol{F}$, Pooled data showing the effects of CNQX on mIPSC frequency. Box-and-whisker plots indicate the median (white line), the 25th-75th percentiles (gray box) and the 10th-90th percentiles (black whiskers); circles and crosses represent individual and mean values, respectively; ${ }^{* * *} p<0.001$ (Wilcoxon signed-rank test vs 1). Hashes denote results of Mann-Whitney U tests (\#\#\# <0.001) performed following Kruskal-Wallis tests that revealed differences among the groups in terms of normalized mIPSC frequency (MLIs: $\chi_{(3)}^{2}=20.9, p=0.00011 ;$ NBQX group not illustrated). G, Representative plot of resting membrane potential from a P14 wild-type MLI calculated using an all-point histogram for each $4 \mathrm{~s}$ division of the voltage record. CNQX produced a $6.3 \mathrm{mV}$ depolarization that reversed upon washout. $\boldsymbol{H}$, Pooled data from P10 - 14 and P20 -23 wild-type animals. Box-and-whisker plots as described in $\boldsymbol{F}$.

using nonparametric statistical tests: two-sided Wilcoxon matched-pairs tests (paired data) or Mann-Whitney $U$ tests (nonpaired data). Normalized changes were tested using a Wilcoxon signed-rank test. All analyses involving data from $\geq 3$ groups were performed using a Kruskal-Wallis test, followed by pairwise comparisons using Mann-Whitney $U$ tests (with Holm's sequential Bonferroni's correction for multiple comparisons). Correlations were tested using Spearman's rank-order correlation. Statistical tests were performed using $\mathrm{R}$ and RStudio. In the text, all $p$ values are presented as equalities (two significant figures) unless $<0.0001$. In the figures, asterisks denote $p$ values from either Wilcoxon matched-pairs test or Wilcoxon signed-rank test as follows: ${ }^{\star} p<0.05$, ${ }^{* *} p<0.01,{ }^{* * *} p<0.001$. Hashes denote $p$ values from Mann-Whitney $U$ tests; $\# p<0.05, \# \#<<0.01$, \#\#\#p<0.001.

\section{Results}

CNQX enhances spontaneous release at MLI-MLI synapses In recordings from cerebellar MLIs, mIPSC frequency is known to increase following the activation of presynaptic AMPARs on connected MLIs (Bureau and Mulle, 1998; Liu, 2007; Rossi et al., 2008), which are thought to depolarize the terminal, thereby activating VGCCs (Bureau and Mulle, 1998). When pore-forming AMPAR subunits are associated with TARPs $\gamma-2, \gamma-3, \gamma-4$, or $\gamma-8$, CNQX acts as a partial agonist, whose effects are potentiated by positive allosteric modulators, such as cyclothiazide (Menuz et al., 2007; Bats et al., 2012). We reasoned that if presynaptic AMPARs in MLIs were associated with $\gamma$-2, then CNQX should increase mIPSC frequency. We found that in acute slices from P10-P14 wild-type mice, $20 \mu \mathrm{M}$ CNQX increased mIPSC frequency from $0.54 \pm 0.15$ to $2.66 \pm 0.73 \mathrm{~Hz}(n=11 ; p=0.00098$, Wilcoxon matched-pairs test; Fig. $1 A, C, F)$. Correspondingly, the phasic charge transfer per second (see Materials and Methods) was increased from $2.27 \pm 0.42$ to $7.24 \pm 1.46 \mathrm{pC}(p=$ 0.00098 , Wilcoxon matched-pairs test; Fig. $1 B)$. These changes were fully reversible on washout of CNQX (Fig. $1 A, B$ ) and oc- 
curred without an alteration in mIPSC amplitude $(198.8 \pm 26.0$ and $175.0 \pm 20.2 \mathrm{pA} ; p=0.58$, Wilcoxon matched-pairs test). Unlike CNQX, the related quinoxaline derivative NBQX (20 $\mu \mathrm{M})$, which does not act as an agonist on TARPed AMPARs (Menuz et al., 2007), failed to increase mIPSC frequency or phasic charge transfer (normalized values, $1.08 \pm 0.11$ and $0.92 \pm$ 0.11 , respectively; $n=4$; both $p=0.63$, Wilcoxon signed-rank test). Consistent with the known developmental expression of presynaptic AMPARs (Bureau and Mulle, 1998; Rossi et al., 2008), CNQX had no effect on mIPSC frequency in slices from P20-P23 wild-type mice (Fig. $1 F$ ).

In MLIs from stg/stg mice that lack $\gamma$-2, CNQX had no effect on mIPSC frequency (normalized frequency, $0.96 \pm 0.10 ; n=7$, $p=1.00$, Wilcoxon signed-rank test; $p<0.0001$ compared with the effect of CNQX in wild-type mice, Mann-Whitney $U$ test) or phasic charge transfer per second (normalized charge, $0.95 \pm$ $0.05 ; p=0.47, p<0.0001$ compared with the effect of CNQX in wild-type mice; Fig. $1 D-F$ ). This suggests that for a major population of presynaptic AMPARs at MLI-MLI synapses, their ability to enhance spontaneous GABA release requires the presence of $\gamma$-2. One alternative interpretation of the CNQX-induced increase in MIPSC frequency is that the activation of somatodendritic AMPARs caused depolarization that spread passively into axonal compartments (Glitsch and Marty, 1999; Christie et al., 2011). Indeed, in current-clamp recordings from MLIs, we found that $20 \mu \mathrm{M}$ CNQX produced an average depolarization of $4.9 \pm$ $0.1 \mathrm{mV}(n=15$; Fig. $1 G, H)$. Importantly, we observed a comparable CNQX-induced depolarization in MLIs from older mice (P20-P23; $4.8 \pm 0.4 \mathrm{mV}, n=7$; Fig. $1 H$ ), yet CNQX had no effect on mIPSC frequency or phasic charge in these cells. This absence of an obligate link between somatodendritic depolarization and altered mIPSC frequency could be taken to support a presynaptic locus of AMPARs in juvenile mice. However, as our data do not address the possibility of an age-dependent change in the axonal spread of depolarization, we examined the effect of CNQX on a class of mIPSCs in MLIs that originate from the activation of presynaptic $\mathrm{GABA}_{\mathrm{A}}$ autoreceptors (pre-mIPCS or preminis; Trigo et al., 2010).

\section{AMPAR-induced increase in pre-mIPSC frequency is absent in stg/stg MLIs}

By recording the frequency of pre-mIPSCs originating from axonal $\mathrm{GABA}_{\mathrm{A}}$ autoreceptors, somatic voltage clamp ensured that any changes in spontaneous release could not result from an effect of somatodendritic AMPARs on membrane potential. mIPSCs in MLIs exhibited a wide range of amplitudes (Fig. 2A$C)$, with the smaller events having slower and more varied rise times than the larger events (Fig. $2 B, C$ ). It is suggested that these slow-rising currents reflect the activation of presynaptic $\mathrm{GABA}_{\mathrm{A}} \mathrm{Rs}$ (pre-mIPSCs; Trigo et al., 2010). In support of this view, we found that the slow mIPSCs were absent from MLIs of P20-P23 wild-type mice (Fig. 2D), consistent with the developmental loss of presynaptic GABA $\mathrm{A}_{\mathrm{A}}$ after P15 (Trigo et al., 2007). As shown in Figure $2 E, H$, the frequency of these small, slow-rising pre-mIPSCs was approximately tripled in the presence of $20 \mu \mathrm{M} C N Q X$ (from $0.05 \pm 0.01$ to $0.17 \pm 0.06 \mathrm{~Hz} ; n=$ $11, p=0.019$; Wilcoxon matched-pairs test). This result suggests that in the absence of somatic depolarization, AMPAR activation can modify GABA release from MLIs, and that this effect is most likely mediated by $\gamma$-2-associated presynaptic AMPARs.

Can presynaptic AMPARs, like somatodendritic AMPARs (Bats et al., 2012), function when associated with $\gamma$-7 or without a TARP? While CNQX will activate only $\gamma$-2-associated AMPARs in MLIs, the full agonist AMPA would be expected to activate AMPARs and enhance spontaneous GABA release, regardless of TARP association. In wild-type MLIs, $2 \mu \mathrm{M}$ AMPA increased the frequency of pre-mIPSCs (from $0.03 \pm 0.01$ to $0.65 \pm 0.14 \mathrm{~Hz}$; $n=9, p=0.012$; Fig. $2 F, H)$, but had no effect in recordings from stg/stg MLIs ( $0.05 \pm 0.01$ to $0.08 \pm 0.05 \mathrm{~Hz} ; n=11 ; p=0.58 ; p=$ 0.0044 vs wild-type MLIs, Mann-Whitney $U$ test; Fig. $2 G, H$ ). Thus, without $\gamma-2$, presynaptic AMPARs are either not trafficked to presynaptic sites or are unable to generate sufficient charge transfer to depolarize the membrane and activate VGCCs.

While our mIPSC results suggest that $\gamma$-2-associated presynaptic AMPARs are found at MLI-MLI synapses, the AMPARinduced increase in pre-mIPSC frequency could reflect, in part, the activation of presynaptic receptors at MLI-Purkinje cell synapses. MLI boutons that contact other MLIs predominantly contain GluA2-lacking CP-AMPARs, while MLI-Purkinje cell boutons contain mostly GluA2-containing CI-AMPARs (Rossi et al., 2008). Given that regulation of AMPARs by TARP isoforms depends on their subunit composition (Bats et al., 2012; Studniarczyk et al., 2013), we next examined whether AMPARs at MLI-Purkinje cell boutons differed from those at MLI-MLI boutons in their dependence on $\gamma-2$.

\section{CNQX enhances spontaneous GABA release on to Purkinje cells in the presence of cyclothiazide}

When recording from Purkinje cells in acute slices, CNQX did not affect mIPSC frequency, even when the concentration was doubled from 20 to $40 \mu \mathrm{M}(4.1 \pm 0.9$ vs $4.3 \pm 1.1 \mathrm{~Hz} ; n=10, p=$ 0.43 , Wilcoxon matched-pairs tests; Fig. $3 E$ ). However, when the slices were preincubated with $50 \mu \mathrm{M}$ cyclothiazide, $40 \mu \mathrm{M}$ CNQX increased both mIPSC frequency and phasic charge transfer per second (from $5.4 \pm 0.9$ to $13.7 \pm 3.0 \mathrm{~Hz}$ and from $8.9 \pm 1.9$ to $21.6 \pm 6.2 \mathrm{pC} ; n=11$, both $p=0.00098$; Fig. $3 A, B, E)$. This lack of effect of CNQX, in the absence of cyclothiazide, suggests a target-dependent difference in CNQX efficacy, which could reflect differences in AMPAR subunit expression (Rusakov et al., 2005; Rossi et al., 2008), AMPAR flip/flop splicing differences (Menuz et al., 2007), or TARP differences (Bats et al., 2012). In all subsequent recordings from Purkinje cells, $50 \mu \mathrm{M}$ cyclothiazide was present whenever CNQX was applied. Of note, $40 \mu \mathrm{M}$ CNQX (plus cyclothiazide) had no effect on mIPSC frequency in Purkinje cells from P20-P23 wild-type mice (Fig. 3E), nor in Purkinje cells from P10-P14 stg/stg mice (normalized frequency, $0.98 \pm 0.09 ; n=5, p=0.81$, Wilcoxon signed-rank test; $p=$ 0.00092 compared with the effect of CNQX in wild-type mice, Mann-Whitney $U$ test; Fig. 3C-E). However, as with the MLI recordings, subthreshold depolarization following the activation of somatodendritic AMPARs may have contributed to the increase in mIPSC frequency. To circumvent this and limit our study to AMPARs at MLI-Purkinje cell boutons, we next examined the effects of AMPAR activation in dissociated Purkinje cells to which functional MLI presynaptic terminals remained attached (Akaike and Moorhouse, 2003).

\section{Presynaptic CI-AMPARs are unable to modulate GABA release in the absence of $\boldsymbol{\gamma}-2$}

Purkinje cells were mechanically dissociated from acute cerebellar slices of P10-P14 wild-type mice (see Materials and Methods). The cells, which were identified by their large soma and characteristic remains of the apical dendrite (Fig. $4 A$ ), exhibited spontaneous currents with kinetics similar to those recorded from Purkinje cells in acute cerebellar slices (Fig. $4 B, C$ ). In the 
A
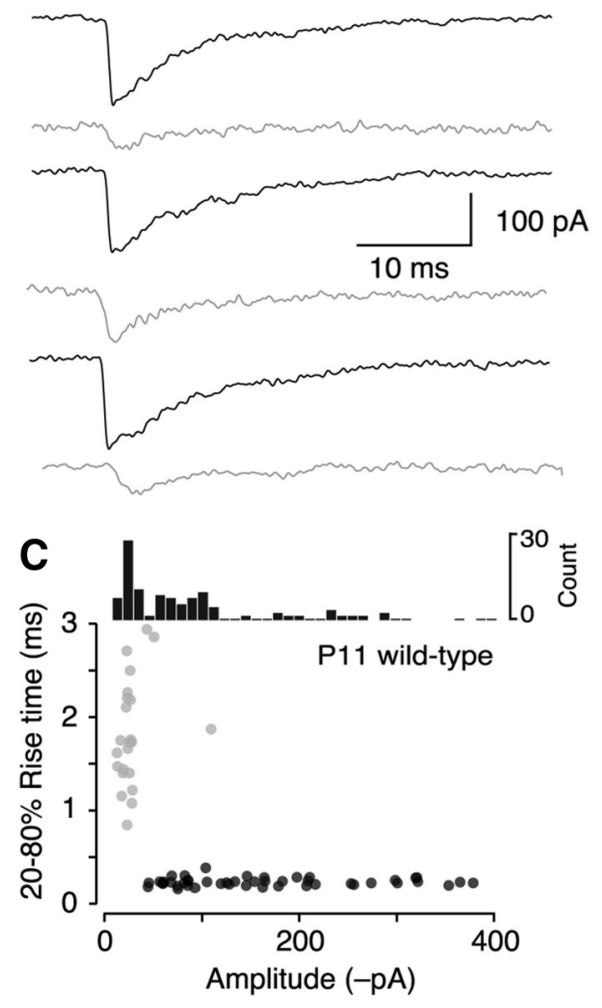

E
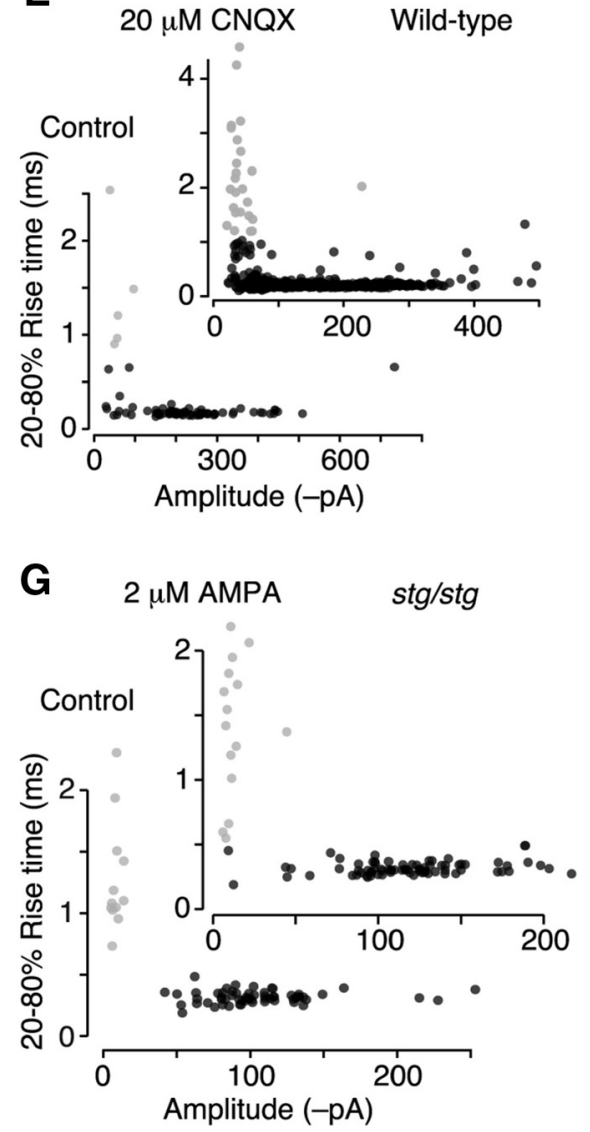

B
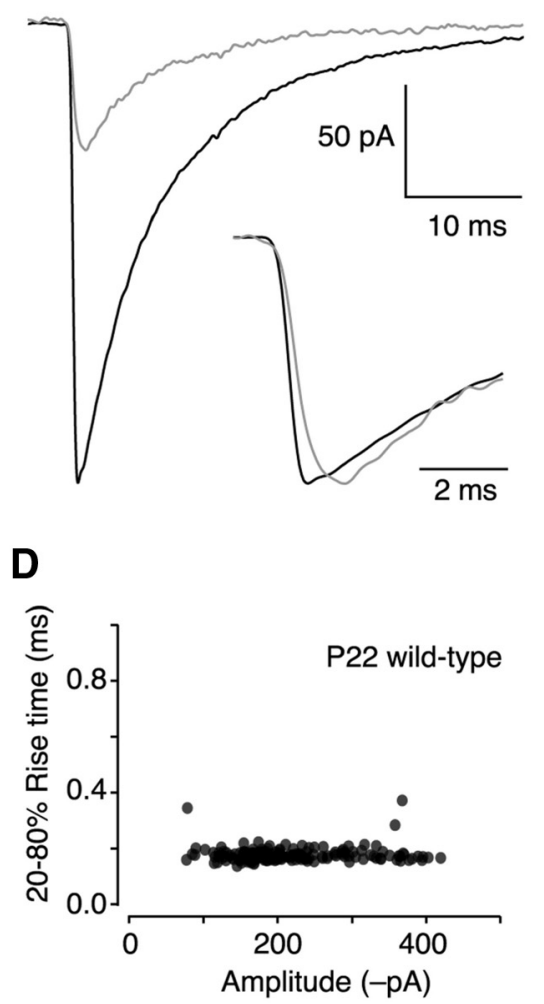

$\mathbf{F}$

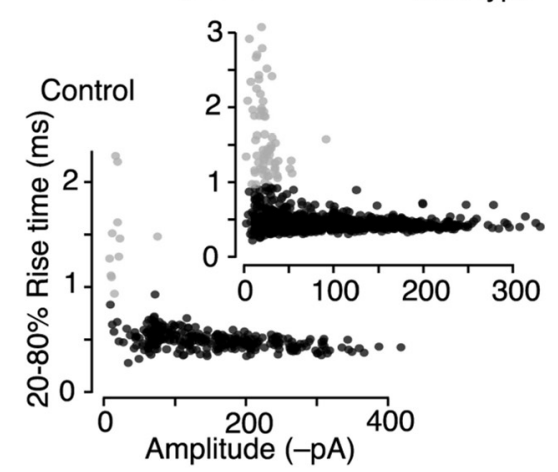

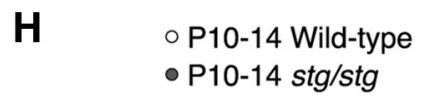

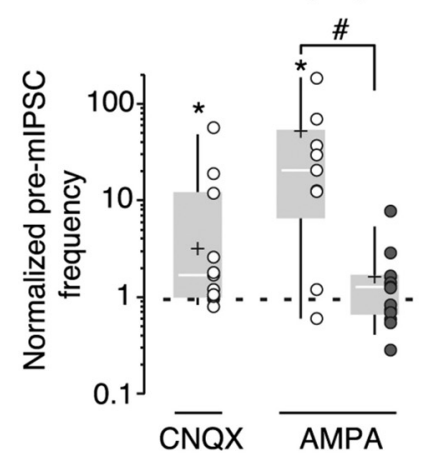

Figure 2. $\quad$ CNQX and AMPA increase frequency of pre-mIPSCS. $\boldsymbol{A}$, Individual representative mIPSCs recorded from a single $\mathrm{P} 12$ wild-type MLI show a mixture of large fast-rising events (black) and low-amplitude slow-rising events (gray). $\boldsymbol{B}$, Averages of the two classes of events recorded from the MLI in $\boldsymbol{A}$ reveals a clear difference in amplitudes. Inset, When normalized to their peak

presence of TTX, all mechanically dissociated Purkinje cells displayed mIPSCs, with a mean peak amplitude (at $-70 \mathrm{mV}$ ) of $-262 \pm 28 \mathrm{pA}$ and $37 \%$ decay time of $6.6 \pm 0.7 \mathrm{~ms}(n=16)$. Consistent with the absence of the dendritic tree, the MIPSC frequency $(0.6 \pm 0.1 \mathrm{~Hz})$ was less than that seen in Purkinje cells in acute slices $(3.6 \pm 2.4 \mathrm{~Hz}, n=73)$. The application of $40 \mu \mathrm{M}$ CNQX (plus $50 \mu \mathrm{M}$ cyclothiazide) increased the mIPSC frequency (normalized frequency, $1.57 \pm 0.10 ; n=7, p=$ 0.016 ; Fig. $4 G$ ). In the absence of MLI somata, dendrites, and most of the axons, this CNQX-induced increase in mIPSC frequency can result only from the activation of presynaptic AMPARs.

To address whether $\gamma$-7-associated AMPARs or TARPless AMPARs occur at MLI-Purkinje cell boutons, we next examined the effects of the full agonist AMPA on mIPSC frequency in dissociated Purkinje cells. In wild-type mice, application of $2 \mu \mathrm{M}$ AMPA increased mIPSC frequency (normalized frequency, $2.50 \pm$ 0.39; $n=9, p=0.004$; Fig. $4 D, E, G)$, whereas in cells form $\mathrm{stg} / \mathrm{stg}$ mice AMPA had no effect (normalized frequency, $0.85 \pm 0.09 ; n=11, p=0.12$, Wilcoxon matched-pairs test; $p<0.0001$ compared with wild type, Mann-Whitney $U$ test; Fig. $4 F, G$ ). This suggests that without $\gamma-2$, CI-AMPARs are either not trafficked to the presynaptic terminal or, if present, that they generate insufficient charge transfer to increase the probability of spontaneous release.

We reasoned that if AMPARs could still reach the terminal in stg/stg MLIs, then enhancing their activity might enable such $\gamma$-2-lacking receptors to generate sufficient charge transfer to enhance spontaneous

$\leftarrow$

amplitude, the slower rise of the smaller events is clear. $\boldsymbol{C}$, Combined amplitude histogram and rise-time distribution plotted as a function of mIPSC amplitude from the same P11 MLI recording. The plot of $20-80 \%$ rise time versus peak amplitude shows that small events have slower rise times than large events. Light gray symbols (in this and subsequent panels) indicate pre-mIPSCs identified by cluster analysis (see Materials and Methods). $\boldsymbol{D}$, An equivalent rise time-versusamplitude plot of mIPSCs from a P22 wild-type mouse shows a relatively tight distribution of rise times. $\boldsymbol{E}-\boldsymbol{G}$, Plots of 20 $80 \%$ rise time of individual mIPSCS as a function of peak amplitude before and after application of $20 \mu \mathrm{M}$ CNQX in P10 -P14 wild-type MLIs (E), $2 \mu$ M AMPA in P10-P14 wildtype MLLs $(\boldsymbol{F})$, and $2 \mu \mathrm{M}$ AMPA in P10 -P14stg/stg MLIs (G). $\boldsymbol{H}$, Pooled data show the frequency of slow-rising smallamplitude mIPSCs is increased following treatment with CNQX or AMPA in wild-type P10 -P14 MLIs. In contrast, AMPA treatment had no effect in recordings from P10 -P14 stg/stg MLls. Box-and-whisker plots as in Figure 1. ${ }^{*} p<0.05$ (Wilcoxon signed-rank test). $\# p<0.05$ (Mann-Whitney $U$ test). 
A

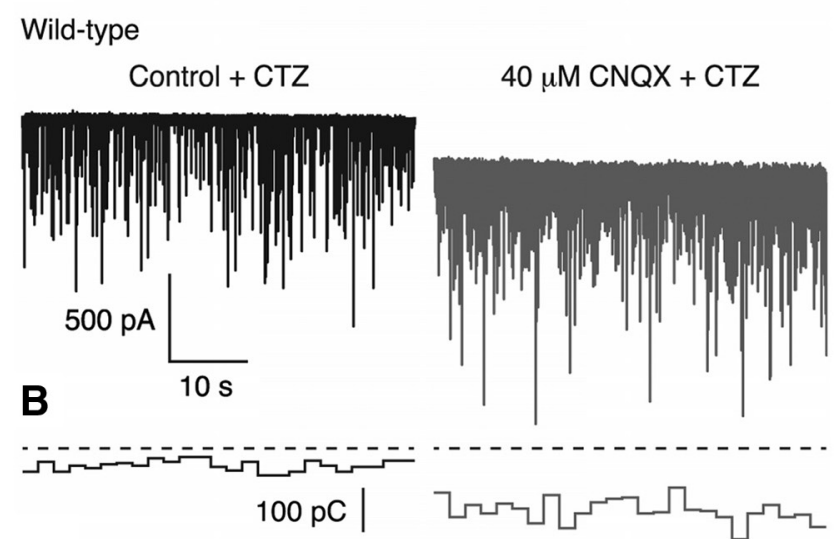

C

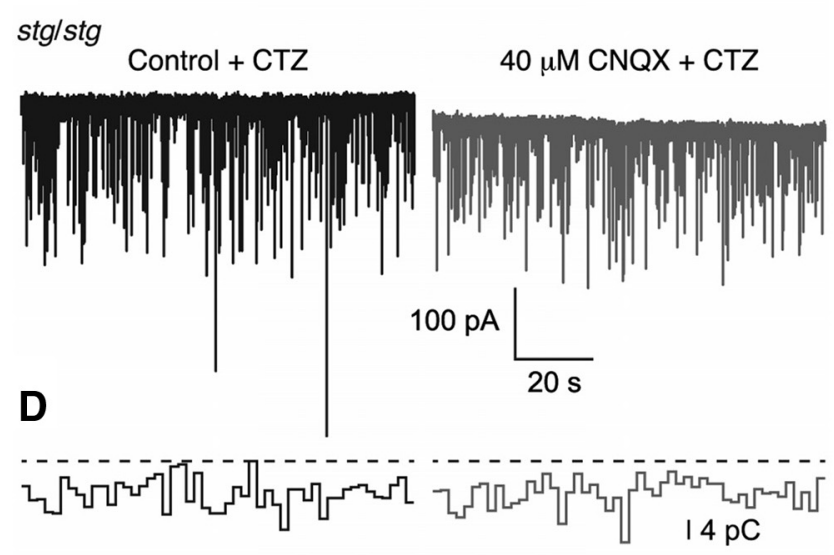

E

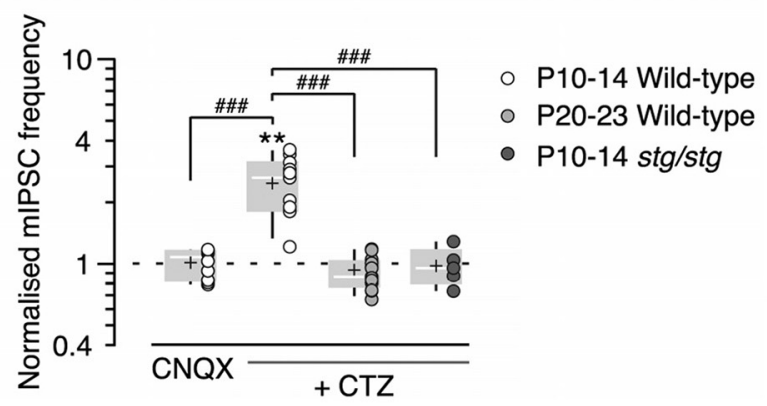

Figure 3. CNQXincreases mIPSC frequency in Purkinje cells when in the presence of cyclothiazide. $\boldsymbol{A}$, Representative current records from a P13 wild-type Purkinje cell showing the CNQXinduced increase in mIPSC frequency. $\boldsymbol{B}$, The corresponding record of phasic charge transfer, calculated every $2 s$ (dashed lines denotes 0 PC). C, D, Representative current and phasic charge records from a P12 stg/stg Purkinje cell, as described in $\boldsymbol{A}$ and $\boldsymbol{B}$. $\boldsymbol{E}$, Pooled data showing the effect of $40 \mu \mathrm{M}$ CNQX on mIPSC frequency normalized to control values in the absence and presence of $50 \mu \mathrm{m}$ cyclothiazide. Box-and-whisker plots as described in Figure 1. ${ }^{* *} p<0.01$ (Wilcoxon signed-rank test versus zero). \#\#\# indicates $p<0.001$ (Mann-Whitney $U$ test vs CNQX in P10-P14 Purkinje cells, following a Kruskal-Wallis test that revealed a significant effect of group $\left.\chi_{(3)}^{2}=23.7, p<0.0001\right)$.

GABA release. Therefore, we next tested the effect of AMPA on mIPSC frequency in mechanically dissociated Purkinje cells from $s t g / s t g$ mice in the presence of the positive allosteric modulator cyclothiazide $(50 \mu \mathrm{M})$. To limit the whole-cell current from AMPARs in the Purkinje cell body, we reduced the driving force by holding the Purkinje cell at $-40 \mathrm{mV}$ and included in the patch pipette $1 \mathrm{~mm}$ philanthotoxin-74, an open-channel blocker of CI-
AMPARs (Jackson et al., 2011). In these conditions, AMPA produced a $1.57 \pm 0.13$-fold increase in mIPSC frequency $(n=6 ; p=$ 0.031; Wilcoxon signed-rank test; Fig. $4 G$ ), which was markedly different from the effect of AMPA alone ( $p=0.00064$; Mann-Whitney $U$ test). This result suggests that in the absence of $\gamma$-2, CI-AMPARs are present presynaptically. Given that AMPARs are still trafficked to presynaptic sites in $s t g / s t g$ mice, the most parsimonious interpretation of this result is that the requirement for $\gamma$ - 2 reflects its influence on receptor gating.

\section{Suppression of evoked GABA release by presynaptic AMPARs} is reduced in stg/stg mice

Contrary to their facilitation of spontaneous release, the activation of presynaptic AMPARs attenuates action potential-evoked release. In cerebellar MLIs and at the calyx of Held, this has been attributed to a G-protein-mediated mechanism (Satake et al., 2004; Rusakov et al., 2005; Takago et al., 2005), potentially independent of cation influx through the AMPAR pore (Wang et al., 1997). Given that presynaptic AMPARs seem to require $\gamma$ - 2 for its influence on gating but not necessarily trafficking, we speculated that AMPAR-mediated inhibition of action potentialevoked release might not require $\gamma-2$.

During repeated climbing fiber stimulation, glutamate escapes uptake mechanisms to activate presynaptic AMPARs on MLI axons (Satake et al., 2000, 2006; Rusakov et al., 2005). The resulting suppression of release causes a reduction of the evoked IPSC amplitude in Purkinje cells (Satake et al., 2000, 2006). We examined whether TARP $\gamma-2$ association is required for presynaptic AMPAR effects on evoked release by comparing the effects of AMPAR activation on GABA release from MLIs of wild-type and $s t g / s t g$ mice.

We made voltage-clamp recordings from Purkinje cells at a holding potential of $-30 \mathrm{mV}$, allowing us to distinguish EPSCs (inward currents) from IPSCs (outward currents). Stimulation, via an extracellular electrode placed in the granule cell layer close to the recorded Purkinje cell (Fig. 5A), produced large, all-ornothing EPSCs that showed paired-pulse depression characteristic of climbing fiber input (Fig. $5 B$ ). A second electrode placed in the lower third of the molecular layer (Fig. 5A) was used to stimulate the axons of MLIs (presumptive basket cells). The amplitudes of five consecutive pairs of IPSCs (Fig. 5C, S2) were measured before and after climbing fiber stimulation (40 stimuli at $50 \mathrm{~Hz}$; Fig. 5C, S1). In slices from wild-type mice we observed a $42 \pm 5 \%$ reduction in the IPSC amplitude (from $1.00 \pm 0.13$ to $0.54 \pm 0.07 \mathrm{nA}, n=13 ; p=0.00024$; Fig. $5 C-E$ ). In slices from $\mathrm{stg} / \mathrm{stg}$ mice this suppression of IPSC amplitude following climbing fiber stimulation was much less $(11 \pm 3 \%, p=0.031, n=6$; $p=0.00088$ vs wild type; Fig. $5 F, G)$.

Climbing fiber stimulation led to an increase in paired-pulse facilitation (Fig. $5 \mathrm{H}$ ), a threefold increase in the CV of IPSC amplitude (normalized CV, $3.20 \pm 0.85 ; n=13 ; p=0.00073$ ) and, across all recordings, the magnitude of the climbing fiberinduced suppression of GABA release correlated with the change in PPR (Fig. 5I). This suggests that the climbing fiber-induced reduction in IPSC amplitude reflects a suppression of release by presynaptic AMPARs. Of note, the decay of climbing fiber EPSCs in Purkinje cells was faster in stg/stg than in wild-type mice (Fig. $5 J)$. While this could reflect altered kinetics of postsynaptic AMPARs at Purkinje cell synapses, a recent study found that the selective deletion of $\gamma$-2 from Purkinje cells led to a reduction in the amplitude of the climbing fiber EPSC, with little apparent change in kinetics (Kawata et al., 2014). The speeding of the EPSC could therefore indicate an altered release of glutamate, or an 
A

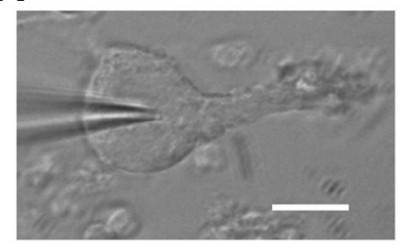

B

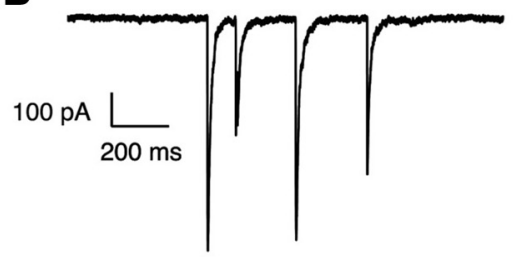

C

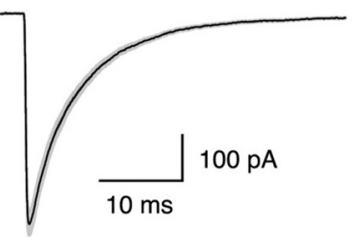

D Wild-type

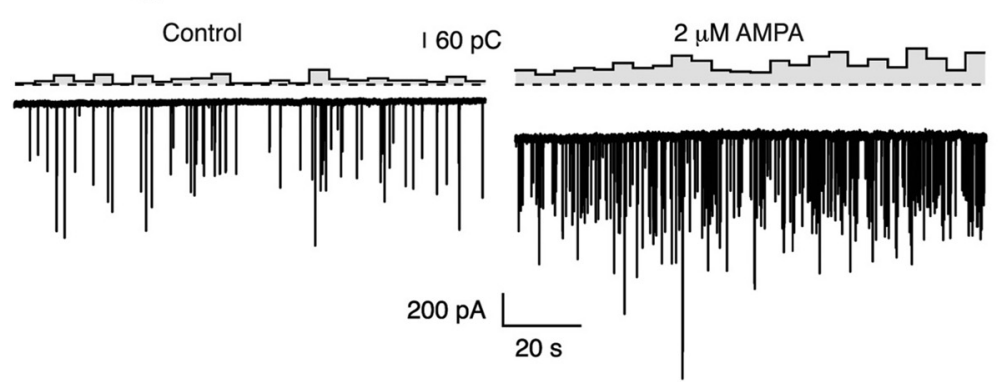

F ${ }_{s t g / s t g}$

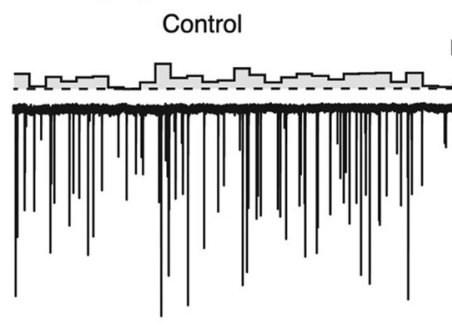

$160 \mathrm{pC}$

$2 \mu \mathrm{M}$ AMPA
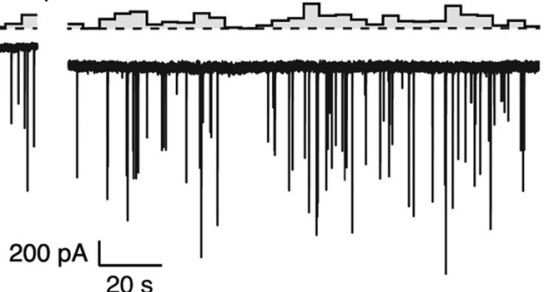

E

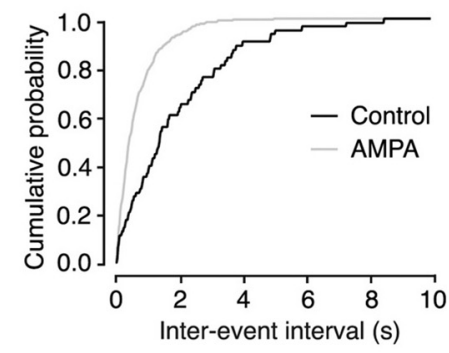

G

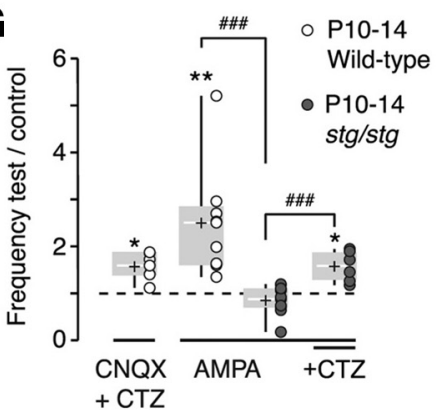

Figure 4. Activation of AMPARs in mechanically dissociated Purkinje cells. $A$, Image of an acutely dissociated cell, illustrating the large soma and truncated proximal dendritic tree. Scale bar, 20 $\mu \mathrm{m} . \boldsymbol{B}$, Representative current record from a Purkinje cell dissociated from a P12 wild-type mouse with typical $\mathrm{mIPSCs}$. C, Average waveform from $48 \mathrm{mIPSCs}$ recorded from the cell in $\boldsymbol{B}$ under control conditions; shaded area denotes SEM. D, Voltage-clamp recording from a P11 mechanically dissociated Purkinje cell showing mIPS(s and the corresponding phasic charge measurements obtained before and during application of $2 \mu \mathrm{M}$ AMPA.E, Cumulative probability histogram shows a clear decrease in the inter-event interval in $2 \mu \mathrm{m} \mathrm{AMPA} \mathrm{(same} \mathrm{cell} \mathrm{as} \mathrm{D;} n=63$ and $466 \mathrm{mIPSCS}$ ). $\boldsymbol{F}$, mIPSCS and corresponding phasic charge transfer from a dissociated Purkinje cell from a P14 stg/stg mouse, in the absence and presence of $2 \mu \mathrm{M}$ AMPA. G, Pooled data show that both $2 \mu \mathrm{m}$ AMPA and 40 $\mu \mathrm{M} C$ NQX [plus $50 \mu \mathrm{m}$ cyclothiazide (CTZ)] increased mIPSC frequency in wild-type Purkinje cells $\left({ }^{*} p<0.05,{ }^{* *} p<0.01\right.$; Wilcoxon signed-rank test vs 1$)$. By comparison, AMPA failed to alter mIPSC frequency in Purkinje cells dissociated from stg/stg mice, unless preincubated with $50 \mu \mathrm{M} \mathrm{CTZ}\left({ }^{*} p<0.05\right.$; Wilcoxon signed-rank test vs 1 ). Hashes denote results of Mann-Whitney $U$ tests (\#\#\#p $<$ $0.001)$ performed following a Kruskal-Wallis test that revealed differences among the groups treated with AMPA in terms of normalized mIPSC frequency $\left(\chi_{(2)}^{2}=19.03, p<0.0001\right)$. Box-andwhisker plots as described in Figure 1.

accelerated clearance (Barbour et al., 1994; Wadiche and Jahr, 2001), or both. Thus, the reduction in the suppression of IPSC amplitude in $s t g / s t g$ mice could result from a difference in the glutamate waveform experienced by presynaptic AMPARs, rather than the specific loss of presynaptic $\gamma-2$. To obviate this potentially confounding issue, we next examined whether MLIPurkinje cell IPSCs in stg/stg and wild-type mice were differentially affected by exogenous AMPAR agonists.

\section{CNQX activates presynaptic $\boldsymbol{\gamma}$-2-associated AMPARs to inhibit evoked GABA release}

For CNQX to sufficiently activate presynaptic AMPARs and enhance mIPSC frequency in Purkinje cells in acute slices, it was necessary to add cyclothiazide (Fig. 3). However, when recording from Purkinje cells in the absence of TTX, we found that $40 \mu \mathrm{M}$ CNQX (plus $50 \mu \mathrm{M}$ cyclothiazide) increased the frequency of IPSCs to such an extent that it was difficult to differentiate extracellularly evoked IPSCs. We therefore reduced the concentration of CNQX to $2 \mu \mathrm{M}$. This concentration (in the presence of $50 \mu \mathrm{M}$ cyclothiazide) produced a $46 \pm 6 \%$ reduction in the amplitude of the first evoked IPSC (Fig. $6 A, B, F$ ), a $35 \pm 5 \%$ increase in the
PPR (Fig. 6C,F), and a $44 \pm 21 \%$ increase in the CV of IPSC amplitude (all measures, $n=6 ; p=0.031 ;$ Fig. $6 F$ ). In cells from stg/stg mice, CNQX had no effect on these measures $(n=6 ; p=$ $1.00,0.31$, and 0.69 ; Fig. $6 D-F$ ). These results are consistent with the idea that the presynaptic AMPARs responsible for the attenuation of evoked GABA release at MLI-Purkinje cell synapses require $\gamma$-2 association. However, as MLI firing was increased by CNQX (data not shown), it remained possible that the reduction in the probability of release simply reflected this increase in firing (Kondo and Marty, 1998). Thus, it was necessary to determine whether a reduction in action potential-driven release could occur in the absence of changes in presynaptic firing. To achieve this, we turned again to mechanically dissociated Purkinje cells and examined the effects of AMPAR activation on evoked GABA release.

\section{CNQX reduces evoked release probability independent of changes in MLI firing}

To evoke currents from adherent boutons on mechanically dissociated Purkinje cells, a patch pipette delivering a current pulse was scanned across the cell surface. At specific locations that were 
spatially restricted, currents could be reliably evoked. These required activation of voltage-gated sodium channels and were mediated by postsynaptic $\mathrm{GABA}_{\mathrm{A}} \mathrm{Rs}$, as they could be completely blocked by either TTX $(1 \mu \mathrm{M})$ or SR-95531 (20 $\mu \mathrm{M}$; Fig. $7 A, B)$. In cells from wild-type mice, application of $2 \mu \mathrm{M}$ CNQX (plus $50 \mu \mathrm{M}$ cyclothiazide) produced a $30 \pm 4 \%$ reduction in the amplitude of the evoked IPSCs, a $3.1 \pm 0.6$-fold increase in the failure rate, and a $1.4 \pm 0.1$-fold increase in the CV of IPSC amplitude (all measures, $n=7 ; p=0.016$; Fig. $7 C$ ). This result demonstrates that AMPAR-mediated suppression of evoked GABA release can occur independently of changes in MLI firing and confirms that, as with their effects on spontaneous release, AMPARmediated inhibition of evoked GABA release requires $\gamma$-2 association.

\section{Discussion}

Our results establish that presynaptic AMPARs require the association of TARP $\gamma-2$ to allow them to modulate GABA release. As our functional data suggest that CI-AMPARs can reach axonal varicosities in the absence of $\gamma$-2, we propose that the dependence on $\gamma$-2 reflects its influence on AMPAR gating. The resulting increase in steady-state charge transfer allows depolarization of the bouton membrane sufficient to enhance spontaneous release and reduce action potential-evoked release.

\section{Alternative explanations for the observed modulation of release probability}

In addition to the activation of presynaptic AMPARs, there are several alternative explanations for the effects we observed. First, exogenous AMPAR agonists could have activated somatodendritic AMPARs in MLIs and influenced release probability by causing subthreshold depolarization (Christie et al., 2011) or by increasing firing (Kondo and Marty, 1998). We were careful to rule out these possibilities by examining pre-mIPSCs in MLIs or recording from mechanically dissociated Purkinje cells, both of which confined the site of release probability modulation to presynaptic terminals.

A second possibility is that exogenous AMPAR agonists, or climbing fiber stimulation, caused the release of a retrograde messenger from the Purkinje cell that increased the frequency of mIPSCs and/or reduced the amplitude of evoked IPSCs. Retrograde release of glutamate from Purkinje cells can activate both presynaptic NMDARs and metabotropic glutamate
A

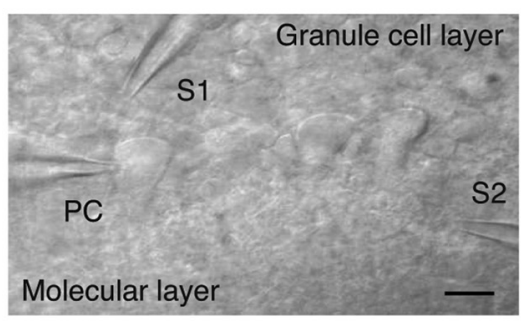

C
B

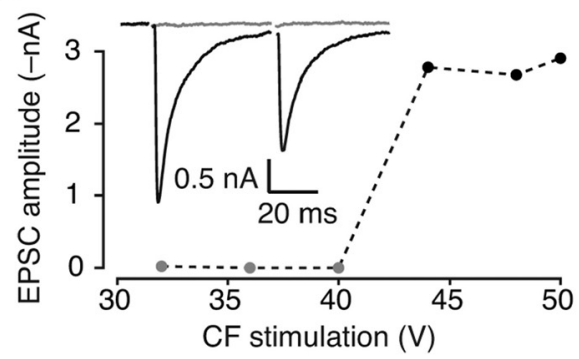

S2

$\frac{a b}{\Lambda_{W t} \wedge}$

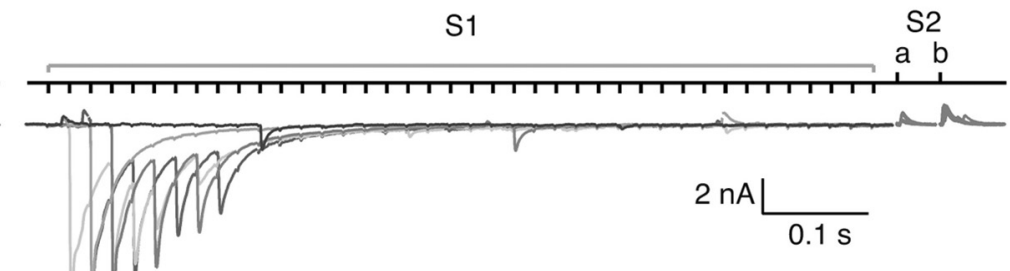

D
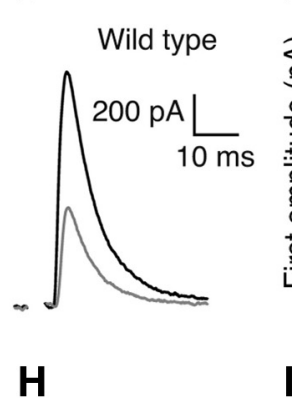

E

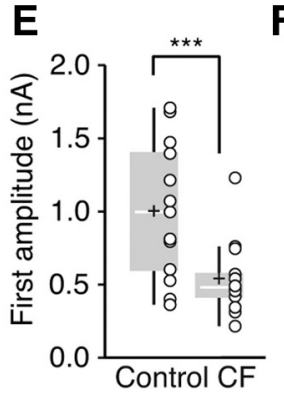

$\mathbf{F}$

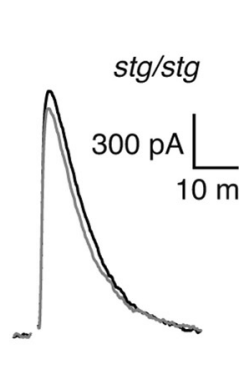

I

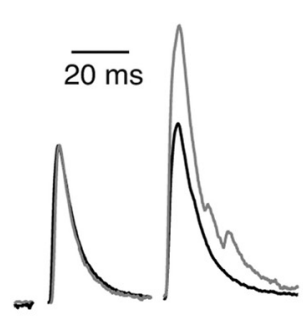

- pre CF - post CF

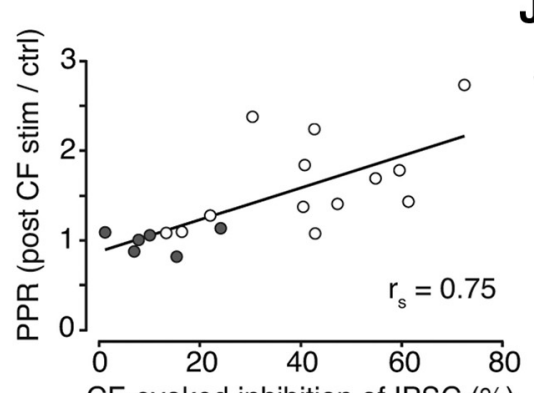

CF-evoked inhibition of IPSC (\%)

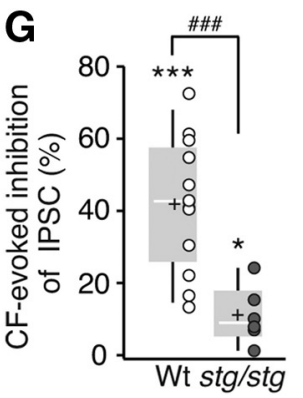

J
Figure 5. Climbing fiber stimulation-induced inhibition of evoked IPSC s is attenuated in Purkinje cells from stg/stg mice. $A$, Image of a sagittal cerebellar slice (P11) showing the position of pipettes used for climbing fiber and MLI stimulation (S1, granule cell layer; S2, inner molecular layer). The recording electrode is on the soma of the Purkinje cell (PC). Scale bar, $20 \mu \mathrm{m}$. $\boldsymbol{B}$, Inset shows representative records of climbing fiber-evoked EPSCs recorded in a Purkinje cell from a wild-type mouse (P10). Failures (gray) were seen with $40 \mathrm{~V}$ stimuli, while successes (black) were seen with $44 \mathrm{~V}$ stimuli. The currents showed characteristic paired-pulse depression and the corresponding plot of peak amplitude shows responses were all or nothing with increasing stimulus voltage. $C$, Representative currents from a Purkinje cell in a slice from a P11 wild-type (Wt) mouse showing IPSCs evoked by paired-pulse MLIstimulation, before(S2, a and b; black) and after (S2, a and b; gray) climbing fiber stimulation ( $\mathrm{S} 1 ; 40$ stimuli at $50 \mathrm{~Hz}$ ). The protocol was repeated five times and responses overlaid; climbing fiberevoked EPSCS are shown as different shades of gray. D, Representative averaged IPSCs from recordings of the type shown in C(S2a pre-CF and S2a post-CF), with consistent trace coloring for identification. $\boldsymbol{E}$, Pooled data showing the climbing fiber (CF)-induced inhibition of IPSC peak amplitude in wild-type Purkinje cells. Box-and-whisker plots as in Figure 1, ${ }^{* * *} p<0.001$ (Wilcoxon signed-rank test vs 0 ). $\boldsymbol{F}$, Averaged IPSCs from a representative stg/stg Purkinje cell recording of the type shown in C (records as in D). G, Pooled data showing the climbing fiber-induced inhibition of IPSC peak amplitude (calculated as 100-[S2a post-CF/S2a pre-CF]) in wild-type and stg/stg Purkinje cells. Box-and-whisker plots are as described in Figure 1, ${ }^{* * *} p<0.001,{ }^{*} p<0.05$ (Wilcoxon signed-rank test vs 0 ). \#\#\#p $<0.001$, wild-type versus stg/stg (Mann-Whitney $\boldsymbol{U}$ test). $\boldsymbol{H}$, Currents enlarged from $\boldsymbol{C}$, showing that climbing fiber stimulation increased the facilitation of successive IPSCS (on average normalized PPR was increased by $1.65 \pm 0.041$-fold, $p=0.00024$; Wilcoxon signed-rank test vs 1). $I$, Scatterplot showing the relationship between the climbing fiber-evoked change in PPR and the degree of IPSC inhibition (Spearmann's rank-order correlation, $r_{s^{\prime}} p=0.0003$ ). J, Representative climbing fiber-evoked EPSCs from a P11 stg/stg mouse (gray) overlaid on the wild-type (Wt) currents from $B$ (black). Compared with climbing fiber-evoked EPSCs from wild-type $(n=7)$, those from stg/stg $(n=$ 4) exhibited faster $10-90 \%$ rise times ( $0.58 \pm 0.04 \mathrm{vs} 0.97 \pm 0.10 \mathrm{~ms} ; p<0.01$ ) and $37 \%$ decay times ( $2.65 \pm 0.34 \mathrm{vs} 10.02 \pm 1.78 \mathrm{~ms}$; $p<0.01$ ), although EPSC amplitude was unchanged ( $1.68 \pm 0.48 \mathrm{vs} 2.27 \pm 0.46 \mathrm{nA} ; p=0.53$ ). The firstEPSCs evoked by any pair or train of stimuli were analyzed. $p$ values are from Mann-Whitney $U$ tests. 
A P10-14 Wild-type (+ CTZ)

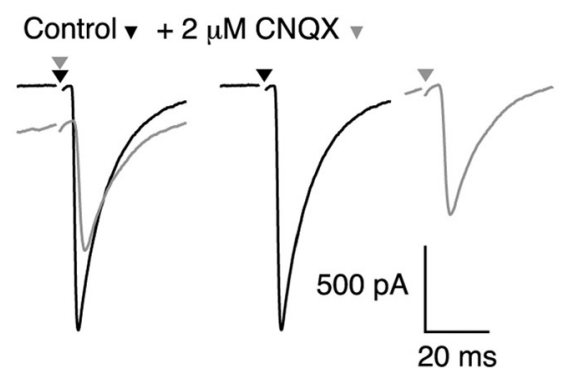

\section{B P10-14 Wild-type}

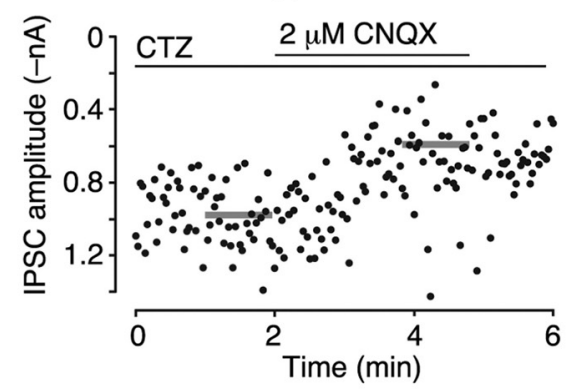

C
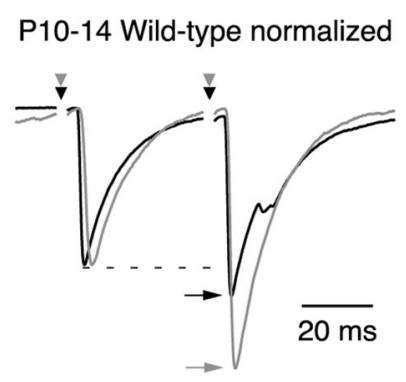

D $\mathrm{P} 10-14 \mathrm{stg} / \mathrm{stg}(+\mathrm{CTZ})$

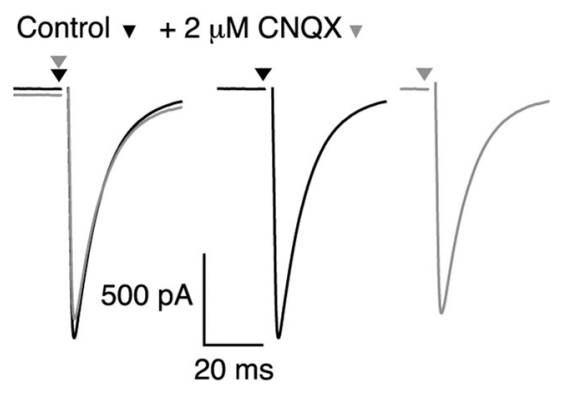

E $\quad$ P10-14 stg/stg normalized

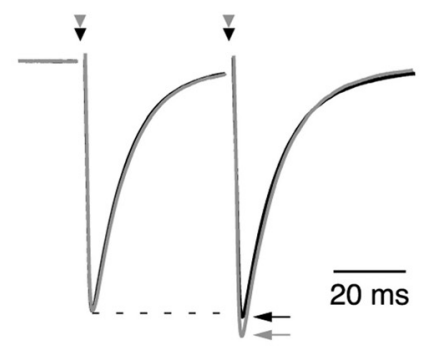

$\mathbf{F}$

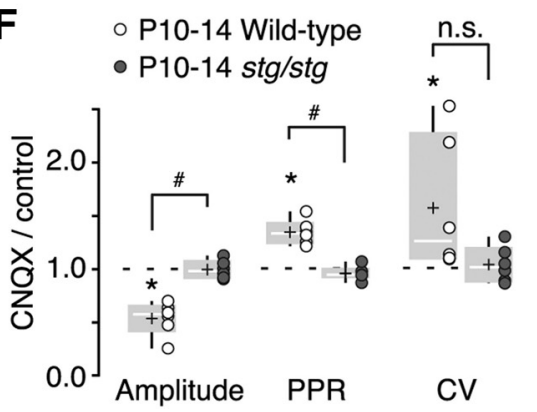

Figure 6. CNQX reduces evoked IPSC amplitude and release probability. All recordings were performed in the presence of $50 \mu \mathrm{M}$ cyclothiazide. $A$, Averaged evoked IPSCs from a representative P10 wild-type Purkinje cell. The records show only the first IPSC from paired stimulation. Superimposed traces (left) were aligned to a common baseline (right) to illustrate the reduced IPSC amplitude in $2 \mu \mathrm{M}$ CNQX (gray) compared with control (black). Note, the relatively unsteady baseline in CNQX reflects the high frequency of spontaneous IPSCs following CNQX application, resulting from increased MLI excitability. In addition, the shift in the baseline current reflects the CNQX-mediated activation of TARP-associated somatodendritic AMPARs in the Purkinje cell. $\boldsymbol{B}$, Representative time course of the CNQX-induced reduction in evoked IPSC peak amplitude in a wild-type Purkinje cell (P10). Horizontal gray bars indicate the time periods over which average IPSC amplitudes were calculated. C, Paired evoked IPSCS (from the same P10 wild-type recording in $\boldsymbol{A}$ ) were scaled to the first IPSC and showed a pronounced increase in PPR in $2 \mu \mathrm{M}$ CNQX (gray) compared with control (black). D, E, Same as $\boldsymbol{A}$ and $\boldsymbol{C}$ for a representative P11 stg/stg Purkinje cell. $\boldsymbol{F}$, Pooled data showing inhibition of IPSC peak amplitude, enhancement of PPR, and increased CV of the first IPSC by $2 \mu \mathrm{m}$ CNQX in wild-type Purkinje cells (black box). ${ }^{*} p<$ 0.05 (Wilcoxon signed-rank test vs 1 ). These effects were absent in stg/stg neurons. \#p $<0.05$ wild type vs stg/stg (Mann-Whitney $U$ test). Box-and-whisker plots are as described in Figure 1.

(mGluR) 2/3 receptors (Glitsch et al., 1996; Duguid and Smart, 2004). As the NMDAR antagonist AP5 was always included in our extracellular solutions, we can rule out any involvement of NMDARs. Moreover, as presynaptic mGluRs act to suppress spontaneous release from MLI boutons (Glitsch et al., 1996), their activation cannot explain the increase in the frequency of mIPSCs that we observed following application of AMPAR agonists. In addition, the suppression of evoked IPSC amplitude, following either climbing fiber stimulation or application of AMPA or kainate, has been shown to be unaffected by the mGluR antagonists $\alpha$-methyl-4-carboxyphenylglycine (MCPG) and $\alpha$-cyclopropyl-4-phosphonophenylglycine (CPPG; Satake et al., $2000,2004)$. By contrast, the suppression of evoked IPSC ampli- tude is strongly attenuated by application of either the AMPAR antagonists GYKI 53655 (Satake et al., 2000) or SYM2206 (Satake et al., 2006) or by the nonselective glutamate receptor blocker kyneurate (Satake et al., 2004).

Retrograde release of the endocannabinoid 2-arachidonoylglycerol can also occur at MLI-Purkinje cell synapses following either elevation of postsynaptic calcium (Ohno-Shosaku et al., 2001; Wilson and Nicoll, 2001) or activation of postsynaptic mGluR1 (Galante and Diana, 2004). The resulting activation of cannabinoid-1 receptors at MLI boutons would depress GABA release (Galante and Diana, 2004). Again, this is incompatible with the increased frequency of mIPSCs that we observed following AMPAR agonist application. In addition, as Satake et al. (2004) showed, the suppression of evoked IPSC amplitude following treatment with AMPA or kainate is not affected by the cannabinoid- 1 receptor antagonist $N$-(piperidin-1-yl)-5-(4-iodophenyl)-1-(2,4-dichlorophenyl)-4-methyl$1 H$-pyrazole-3-carboxamide (AM 251).

Last, TARPs have a secondary structure that shares $\sim 25 \%$ identity with the $\gamma-1$ subunit of VGCCs found in skeletal muscle (Letts et al., 1998). High-voltageactivated N-type and P/Q-type VGCCs are responsible for mediating action potential-dependent release from MLIs (Forti et al., 2000). Could the attenuated effects of CNQX, AMPA, or climbing fiber stimulation we observed in $\mathrm{stg} / \mathrm{stg}$ mice have resulted from the absence of an interaction between $\gamma-2$ and VGCCs? Most studies that have examined either P/Q-type channels in heterologous expression systems (Letts et al., 1998; Klugbauer et al., 2000; Rousset et al., 2001; Moss et al., 2003) or a mixed P/Q-type, $\mathrm{N}$-type, L-type population in cerebellar granule cells (Chen et al., 2000) have found $\gamma$-2 to have no effect on VGCC activation kinetics, voltage dependence of activation, or peak current amplitude. Some, but not all, studies found $\gamma-2$ association to negatively shift the voltage dependence for steady-state inactivation (Letts et al., 1998; Klugbauer et al., 2000; Rousset et al., 2001). Thus, fewer $\gamma$-2-associated VGCCs would be available for activation at rest. By contrast, the current mediated by a mixed population of high-voltage-activated VGCCs in thalamic relay neurons was increased in stg/stg compared with wild-type mice (Zhang et al., 2002). In agreement, Kang et al. (2001) found that the N-type VGCC current in Xenopus oocytes was reduced by $\gamma$-2. These inhibitory, or modestly potentiating, effects of $\gamma-2$ on VGCCs suggest that the absence of this potential interaction is unlikely to explain the attenuated or abolished effects on release probability of AMPARs in $s t g / s t g$ MLIs. 

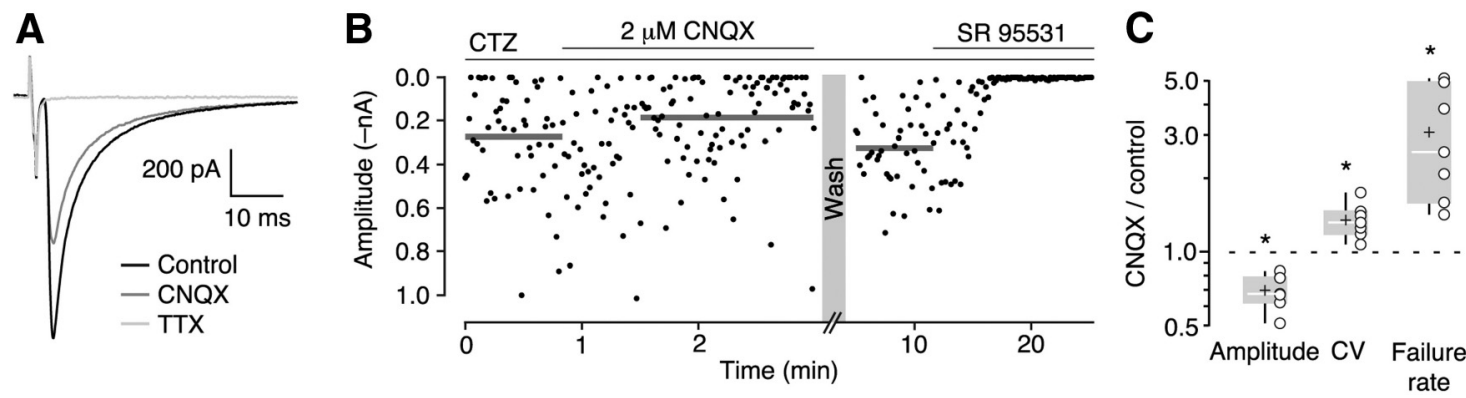

Figure 7. CNQX effects on evoked release are preserved in Purkinje cells dissociated from P10-P14 mice. All recordings were performed in the presence of $50 \mu \mathrm{m}$ cyclothiazide. A, Stimulation of a single adherent MLI bouton on an acutely dissociated P12 Purkinje cell evoked IPSCs that were blocked by $1 \mu \mathrm{m} \mathrm{TTX} \mathrm{(light} \mathrm{gray} \mathrm{trace).} \mathrm{The} \mathrm{amplitude} \mathrm{of} \mathrm{the} \mathrm{average} \mathrm{IPSC} \mathrm{waveform} \mathrm{decreased} \mathrm{in}$ $2 \mu \mathrm{M}$ CNQX (dark gray trace). B, Sample time course of CNQX-induced reduction in evoked IPSC peak amplitude from a different dissociated Purkinje cell (P13). The amplitude recovered to original values following removal of CNQX, and events were abolished completely by application of the GABA R blocker SR $95531(20 \mu \mathrm{M})$. Horizontal gray bars indicate the time periods from which IPSC measurements were averaged. C, Pooled data showing inhibition of IPSC peak amplitude, increased CV of IPSC amplitude, and increased failure rate in the presence of CNQX. ${ }^{*} p<0.05$ (Wilcoxon signed-rank test vs 1). Box-and-whisker plots as described in Figure 1.

\section{$\gamma$-2 Enhances presynaptic AMPAR gating but is not essential for AMPAR trafficking}

Previous studies have shown that $\gamma$-2 increases the single-channel conductance of recombinant CP-AMPARs (homomeric GluA1, GluA3, and GluA4) and CI-AMPARs (homomeric GluA2 and heteromeric GluA2/4) by 50-80\% (Soto et al., 2009; Jackson et al., 2011; Coombs et al., 2012). A corresponding difference in conductance has also been described for native AMPARs that were inferred to be either TARPed or TARPless (Bats et al., 2012). For recombinant receptors, $\gamma$ - 2 also slows desensitization by $20-$ 100\% (Turetsky et al., 2005; Milstein et al., 2007; Suzuki et al., 2008; Soto et al., 2009; Coombs et al., 2012) and increases glutamate potency; the $\mathrm{EC}_{50}$ value of GluA1 homomers is reduced by 2-6-fold (Yamazaki et al., 2004; Priel et al., 2005; Tomita et al., 2005; Kott et al., 2007). What might be the expected effect of $\gamma$-2 on presynaptic AMPARs at MLI-Purkinje cell boutons? As these receptors are of the CI subtype (Rusakov et al., 2005; Satake et al., 2006), and given that MLIs are suggested to express all GluA subunits (Rossi et al., 2008), they are likely to be heteromeric. Data from heterologously expressed heteromeric AMPARs (GluA2(R)/4(Q); Jackson et al., 2011), suggests that $\gamma$-2 association causes a fourfold increase in open probability at steady-state $\left(P_{\mathrm{o}, \mathrm{ss}}\right)$ and increases the single-channel conductance $(g)$ from 6.0 to $10.8 \mathrm{pS}$. Accordingly, the current through a single AMPAR $\left(i_{\mathrm{AMPA}}=P_{\mathrm{o}, \mathrm{ss}} \times g\right)$ would be increased $>7$-fold by $\gamma-2$.

Given the target-specific heterogeneity in the subunit composition of presynaptic AMPARs (Rossi et al., 2008), $\gamma$-2 association may confer greater enhancement of AMPAR effects on release probability at MLI-MLI boutons than at MLI-Purkinje cell boutons. For CP-AMPARs present at MLI-MLI boutons, $\gamma-2$ would be expected to attenuate (and speed recovery from) their voltagedependent block by endogenous intracellular polyamines (Soto et al., 2007) and enhance relative calcium permeability (Kott et al., 2007; Coombs et al., 2012). These additional effects may have contributed to the apparent target-dependent difference in CNQX efficacy, where the partial agonist was able to increase mIPSC frequency in MLIs but did so only in Purkinje cells when cylcothiazide was present.

Overall, $\gamma$-2 would be expected to considerably enhance charge transfer via presynaptic CI-AMPARs and CP-AMPARs, and increase direct calcium entry via CP-AMPARs. Increased charge transfer would produce a correspondingly larger terminal depolarization and thus enhance the activation of VGCCs. Such amplification could allow the enhancement of spontaneous release or the attenuation of evoked release by a relatively small number of AMPARs, which may be important in the spatially constrained environment of a presynaptic site. In addition, the moderately increased glutamate potency might be expected to broaden the spatial extent over which glutamate spillover influences GABA release, by increasing the number of MLI boutons affected.

For postsynaptic AMPARs, TARPs are known to promote their dendrite-selective sorting (Matsuda et al., 2008), cellsurface delivery (Tomita et al., 2003), and synaptic accumulation (Chen et al., 2000; Bats et al., 2007; Howard et al., 2010). Given that GluA2-containing CI-AMPARs in MLIs are unable to accumulate at postsynaptic sites in the absence of $\gamma$-2 (Bats et al., 2012), it was surprising that presynaptic CI-AMPARs appeared to reach the MLI terminal without $\gamma-2$. The absence of an absolute dependence on TARPs for the trafficking of presynaptic AMPARs is supported by data from hippocampal pyramidal neurons and Purkinje cells. Here, it was found that following AMPAR export from the Golgi apparatus, TARP interaction with the $\mu 4$ subunit of the clathrin-based adapter protein- 4 was necessary for the somatodendritic, but not axonal, targeting of AMPARs (Matsuda et al., 2008). It is possible that axonal targeting could involve suppression of this interaction, potentially through phosphorylation of serine or threonine residues in the TARP C terminal (Matsuda et al., 2008).

\section{Mechanisms underlying the differential effects of presynaptic AMPARs}

Presynaptic AMPARs at MLI terminals have opposing actions on evoked and spontaneous GABA release onto Purkinje cells. AMPARs have been proposed to reduce evoked release by inhibiting VGCCs through an unidentified G-protein pathway (Satake et al., 2004). This was further argued for on the basis that presynaptic AMPARs did not exert an ionotropic effect sufficient to activate VGCCs to a degree that could be detected by calcium imaging (Rusakov et al., 2005). This view is difficult to reconcile with the presynaptic AMPAR-induced increase in MIPSC frequency, which requires the activation of VGCCs (Bureau and Mulle, 1998; Rossi et al., 2008; our own observations). In addition, our data suggest presynaptic AMPAR gating is required for both the reduction of evoked release and the facilitation of spontaneous release.

One possibility is that presynaptic AMPARs produce modest membrane depolarization, leading to only a small increase in VGCC open probability and a nanomolar elevation of interterminal calcium concentration. Although such changes in calcium 
may be difficult to identify using calcium indicators, they have been shown to influence release probability (Awatramani et al., 2005). A suitable analogy is provided by asynchronous release, which also involves relatively small increases in calcium above rest and, at MLI terminals, can weaken subsequent action potential-evoked transmission (Christie et al., 2011). Potential mechanisms for depression of evoked transmission during asynchronous-like release include the depletion of releasable vesicles or the inactivation of release sites (Fioravante and Regehr, 2011). However, for presynaptic AMPARs at MLI terminals, a mechanism that exclusively involves these forms of depression appears unlikely, given that puff application of AMPA was shown to reduce action potential-elicited $\mathrm{Ca}^{2+}$ signals (Rusakov et al., 2005). Alternatively, AMPAR-mediated inhibition of evoked release could reflect inactivation of axonal voltage-gated sodium channels (Graham and Redman, 1994; Zhang and Jackson, 1995; Hori and Takahashi, 2009), decreased input resistance (Cattaert and El Manira, 1999), or a reduced driving force for calcium entry.

Of note, depolarization mediated by presynaptic ligand-gated channels does not necessarily lead to an inhibition of evoked release. For example, glycine and $\mathrm{GABA}_{\mathrm{A}}$ receptors at the calyx of Held also depolarize the membrane and increase VGCC activity, yet they enhance evoked release (Turecek and Trussell, 2001, 2002). The depolarization and resulting increase in basal $\mathrm{Ca}^{2+}$ concentration (Awatramani et al., 2005) is thought to be sufficient to produce a $\mathrm{Ca}^{2+}$-dependent facilitation of $\mathrm{P} / \mathrm{Q}$-type VGCCs, but insufficient to trigger inactivation of sodium channels or other mechanisms that underlie depression (Hori and Takahashi, 2009). Further investigation is required for a complete understanding of the mechanisms underlying the differential actions of presynaptic AMPARs at MLI boutons.

\section{References}

Akaike N, Moorhouse AJ (2003) Techniques: applications of the nervebouton preparation in neuropharmacology. Trends Pharmacol Sci 24: 44-47. CrossRef Medline

Awatramani GB, Price GD, Trussell LO (2005) Modulation of transmitter release by presynaptic resting potential and background calcium levels. Neuron 48:109-121. CrossRef Medline

Barbour B, Keller BU, Llano I, Marty A (1994) Prolonged presence of glutamate during excitatory synaptic transmission to cerebellar Purkinje cells. Neuron 12:1331-1343. CrossRef Medline

Bats C, Groc L, Choquet D (2007) The interaction between stargazin and PSD-95 regulates AMPA receptor surface trafficking. Neuron 53:719734. CrossRef Medline

Bats C, Soto D, Studniarczyk D, Farrant M, Cull-Candy SG (2012) Channel properties reveal differential expression of TARPed and TARPless AMPARs in stargazer neurons. Nat Neurosci 15:853-861. CrossRef Medline

Bureau I, Mulle C (1998) Potentiation of GABAergic synaptic transmission by AMPA receptors in mouse cerebellar stellate cells: changes during development. J Physiol 509:817-831. CrossRef Medline

Cattaert D, El Manira A (1999) Shunting versus inactivation: analysis of presynaptic inhibitory mechanisms in primary afferents of the crayfish. J Neurosci 19:6079-6089. Medline

Chang S, De Camilli P (2001) Glutamate regulates actin-based motility in axonal filopodia. Nat Neurosci 4:787-793. CrossRef Medline

Chen L, Chetkovich DM, Petralia RS, Sweeney NT, Kawasaki Y, Wenthold RJ, Bredt DS, Nicoll RA (2000) Stargazin regulates synaptic targeting of AMPA receptors by two distinct mechanisms. Nature 408:936-943. CrossRef Medline

Christie JM, Chiu DN, Jahr CE (2011) $\mathrm{Ca}^{2+}$-dependent enhancement of release by subthreshold somatic depolarization. Nat Neurosci 14:62-68. CrossRef Medline

Clements JD, Bekkers JM (1997) Detection of spontaneous synaptic events with an optimally scaled template. Biophys J 73:220-229. CrossRef Medline

Contractor A, Mulle C, Swanson GT (2011) Kainate receptors coming of age: milestones of two decades of research. Trends Neurosci 34:154-163. CrossRef Medline

Coombs ID, Soto D, Zonouzi M, Renzi M, Shelley C, Farrant M, Cull-Candy SG (2012) Cornichons modify channel properties of recombinant and glial AMPA receptors. J Neurosci 32:9796-9804. CrossRef Medline

Duguid IC, Smart TG (2004) Retrograde activation of presynaptic NMDA receptors enhances GABA release at cerebellar interneuron-Purkinje cell synapses. Nat Neurosci 7:525-533. CrossRef Medline

Duguid IC, Pankratov Y, Moss GW, Smart TG (2007) Somatodendritic release of glutamate regulates synaptic inhibition in cerebellar Purkinje cells via autocrine mGluR1 activation. J Neurosci 27:12464-12474. CrossRef Medline

Fioravante D, Regehr WG (2011) Short-term forms of presynaptic plasticity. Curr Opin Neurobiol 21:269-274. CrossRef Medline

Forti L, Pouzat C, Llano I (2000) Action potential-evoked $\mathrm{Ca}^{2+}$ signals and calcium channels in axons of developing rat cerebellar interneurones. J Physiol 527:33-48. CrossRef Medline

Fukaya M, Yamazaki M, Sakimura K, Watanabe M (2005) Spatial diversity in gene expression for VDCC gamma subunit family in developing and adult mouse brains. Neurosci Res 53:376-383. CrossRef Medline

Galante M, Diana MA (2004) Group I metabotropic glutamate receptors inhibit GABA release at interneuron-Purkinje cell synapses through endocannabinoid production. J Neurosci 24:4865-4874. CrossRef Medline

Glitsch M, Marty A (1999) Presynaptic effects of NMDA in cerebellar Purkinje cells and interneurons. J Neurosci 19:511-519. Medline

Glitsch M, Llano I, Marty A (1996) Glutamate as a candidate retrograde messenger at interneurone-Purkinje cell synapses of rat cerebellum. J Physiol 497:531-537. CrossRef Medline

Graham B, Redman S (1994) A simulation of action potentials in synaptic boutons during presynaptic inhibition. J Neurophysiol 71:538-549. Medline

Hori T, Takahashi T (2009) Mechanisms underlying short-term modulation of transmitter release by presynaptic depolarization. J Physiol 587: 2987-3000. CrossRef Medline

Howard MA, Elias GM, Elias LA, Swat W, Nicoll RA (2010) The role of SAP97 in synaptic glutamate receptor dynamics. Proc Natl Acad Sci U S A 107:3805-3810. CrossRef Medline

Jackson AC, Nicoll RA (2011) The expanding social network of ionotropic glutamate receptors: TARPs and other transmembrane auxiliary subunits. Neuron 70:178-199. CrossRef Medline

Jackson AC, Milstein AD, Soto D, Farrant M, Cull-Candy SG, Nicoll RA (2011) Probing TARP modulation of AMPA receptor conductance with polyamine toxins. J Neurosci 31:7511-7520. CrossRef Medline

Kang MG, Chen CC, Felix R, Letts VA, Frankel WN, Mori Y, Campbell KP (2001) Biochemical and biophysical evidence for $\gamma 2$ subunit association with neuronal voltage-activated $\mathrm{Ca}^{2+}$ channels. J Biol Chem 276:3291732924. CrossRef Medline

Kawata S, Miyazaki T, Yamazaki M, Mikuni T, Yamasaki M, Hashimoto K, Watanabe M, Sakimura K, Kano M (2014) Global scaling down of excitatory postsynaptic responses in cerebellar Purkinje cells impairs developmental synapse elimination. Cell Rep 8:1119-1129. CrossRef Medline

Klugbauer N, Dai S, Specht V, Lacinová L, Marais E, Bohn G, Hofmann F (2000) A family of $\gamma$-like calcium channel subunits. FEBS Lett 470:189 197. CrossRef Medline

Kondo S, Marty A (1998) Synaptic currents at individual connections among stellate cells in rat cerebellar slices. J Physiol 509:221-232. CrossRef Medline

Kott S, Werner M, Körber C, Hollmann M (2007) Electrophysiological properties of AMPA receptors are differentially modulated depending on the associated member of the TARP family. J Neurosci 27:3780-3789. CrossRef Medline

Letts VA, Felix R, Biddlecome GH, Arikkath J, Mahaffey CL, Valenzuela A, Bartlett FS 2nd, Mori Y, Campbell KP, Frankel WN (1998) The mouse stargazer gene encodes a neuronal $\mathrm{Ca}^{2+}$-channel gamma subunit. Nat Genet 19:340-347. CrossRef Medline

Liu SJ (2007) Biphasic modulation of GABA release from stellate cells by glutamatergic receptor subtypes. J Neurophysiol 98:550-556. CrossRef Medline

Matsuda S, Miura E, Matsuda K, Kakegawa W, Kohda K, Watanabe M, Yuzaki M (2008) Accumulation of AMPA receptors in autophagosomes in neuronal axons lacking adaptor protein AP-4. Neuron 57:730-745. CrossRef Medline 
Menuz K, Stroud RM, Nicoll RA, Hays FA (2007) TARP auxiliary subunits switch AMPA receptor antagonists into partial agonists. Science 318:815817. CrossRef Medline

Milstein AD, Zhou W, Karimzadegan S, Bredt DS, Nicoll RA (2007) TARP subtypes differentially and dose-dependently control synaptic AMPA receptor gating. Neuron 55:905-918. CrossRef Medline

Moss FJ, Dolphin AC, Clare JJ (2003) Human neuronal stargazin-like proteins, $\gamma 2, \gamma 3$ and $\gamma 4$; an investigation of their specific localization in human brain and their influence on CaV2.1 voltage-dependent calcium channels expressed in Xenopus oocytes. BMC Neurosci 4:23. CrossRef Medline

Ng D, Pitcher GM, Szilard RK, Sertié A, Kanisek M, Clapcote SJ, Lipina T, Kalia LV, Joo D, McKerlie C, Cortez M, Roder JC, Salter MW, McInnes RR (2009) Netol is a novel CUB-domain NMDA receptor-interacting protein required for synaptic plasticity and learning. PLoS Biol 7:e41. CrossRef Medline

Ohno-Shosaku T, Maejima T, Kano M (2001) Endogenous cannabinoids mediate retrograde signals from depolarized postsynaptic neurons to presynaptic terminals. Neuron 29:729-738. CrossRef Medline

Pinheiro PS, Mulle C (2008) Presynaptic glutamate receptors: physiological functions and mechanisms of action. Nat Rev Neurosci 9:423-436. CrossRef Medline

Priel A, Kolleker A, Ayalon G, Gillor M, Osten P, Stern-Bach Y (2005) Stargazin reduces desensitization and slows deactivation of the AMPA-type glutamate receptors. J Neurosci 25:2682-2686. CrossRef Medline

Rossi B, Maton G, Collin T (2008) Calcium-permeable presynaptic AMPA receptors in cerebellar molecular layer interneurones. J Physiol 586:5129_ 5145. CrossRef Medline

Rousset M, Cens T, Restituito S, Barrere C, Black JL 3rd, McEnery MW, Charnet $\mathrm{P}$ (2001) Functional roles of $\gamma 2, \gamma 3$ and $\gamma 4$, three new $\mathrm{Ca}^{2+}$ channel subunits, in P/Q-type $\mathrm{Ca}^{2+}$ channel expressed in Xenopus oocytes. J Physiol 532:583-593. CrossRef Medline

Rusakov DA, Saitow F, Lehre KP, Konishi S (2005) Modulation of presynaptic $\mathrm{Ca}^{2+}$ entry by AMPA receptors at individual GABAergic synapses in the cerebellum. J Neurosci 25:4930-4940. CrossRef Medline

Sasaki T, Matsuki N, Ikegaya Y (2011) Action-potential modulation during axonal conduction. Science 331:599-601. CrossRef Medline

Satake S, Saitow F, Yamada J, Konishi S (2000) Synaptic activation of AMPA receptors inhibits GABA release from cerebellar interneurons. Nat Neurosci 3:551-558. CrossRef Medline

Satake S, Saitow F, Rusakov D, Konishi S (2004) AMPA receptor-mediated presynaptic inhibition at cerebellar GABAergic synapses: a characterization of molecular mechanisms. Eur J Neurosci 19:2464-2474. CrossRef Medline

Satake S, Song SY, Cao Q, Satoh H, Rusakov DA, Yanagawa Y, Ling EA, Imoto K, Konishi S (2006) Characterization of AMPA receptors targeted by the climbing fiber transmitter mediating presynaptic inhibition of GABAergic transmission at cerebellar interneuron-Purkinje cell synapses. J Neurosci 26: 2278-2289. CrossRef Medline

Schenk U, Menna E, Kim T, Passafaro M, Chang S, De Camilli P, Matteoli M (2005) A novel pathway for presynaptic mitogen-activated kinase activation via AMPA receptors. J Neurosci 25:1654-1663. CrossRef Medline

Schwenk J, Harmel N, Zolles G, Bildl W, Kulik A, Heimrich B, Chisaka O, Jonas P, Schulte U, Fakler B, Klöcker N (2009) Functional proteomics identify cornichon proteins as auxiliary subunits of AMPA receptors. Science 323:1313-1319. CrossRef Medline

Schwenk J, Harmel N, Brechet A, Zolles G, Berkefeld H, Müller CS, Bildl W, Baehrens D, Hüber B, Kulik A, Klöcker N, Schulte U, Fakler B (2012) High-resolution proteomics unravel architecture and molecular diversity of native AMPA receptor complexes. Neuron 74:621-633. CrossRef Medline

Semyanov A, Kullmann DM (2001) Kainate receptor-dependent axonal depolarization and action potential initiation in interneurons. Nat Neurosci 4:718-723. CrossRef Medline

Shanks NF, Savas JN, Maruo T, Cais O, Hirao A, Oe S, Ghosh A, Noda Y, Greger IH, Yates JR 3rd, Nakagawa T (2012) Differences in AMPA and kainate receptor interactomes facilitate identification of AMPA receptor auxiliary subunit GSG1L. Cell Rep 1:590-598. CrossRef Medline

Soto D, Coombs ID, Kelly L, Farrant M, Cull-Candy SG (2007) Stargazin attenuates intracellular polyamine block of calcium-permeable AMPA receptors. Nat Neurosci 10:1260-1267. CrossRef Medline

Soto D, Coombs ID, Renzi M, Zonouzi M, Farrant M, Cull-Candy SG (2009)
Selective regulation of long-form calcium-permeable AMPA receptors by an atypical TARP, $\gamma-5$. Nat Neurosci 12:277-285. CrossRef Medline

Straub C, Tomita S (2012) The regulation of glutamate receptor trafficking and function by TARPs and other transmembrane auxiliary subunits. Curr Opin Neurobiol 22:488-495. CrossRef Medline

Studniarczyk D, Coombs I, Cull-Candy SG, Farrant M (2013) TARP $\gamma$-7 selectively enhances synaptic expression of calcium-permeable AMPARs. Nat Neurosci 16:1266-1274. CrossRef Medline

Suzuki E, Kessler M, Arai AC (2008) The fast kinetics of AMPA GluR3 receptors is selectively modulated by the TARPs gamma 4 and gamma 8 . Mol Cell Neurosci 38:117-123. CrossRef Medline

Takago H, Nakamura Y, Takahashi T (2005) G protein-dependent presynaptic inhibition mediated by AMPA receptors at the calyx of Held. Proc Natl Acad Sci U S A 102:7368-7373. CrossRef Medline

Tashiro A, Dunaevsky A, Blazeski R, Mason CA, Yuste R (2003) Bidirectional regulation of hippocampal mossy fiber filopodial motility by kainate receptors: a two-step model of synaptogenesis. Neuron 38:773-784. CrossRef Medline

Tomita S, Chen L, Kawasaki Y, Petralia RS, Wenthold RJ, Nicoll RA, Bredt DS (2003) Functional studies and distribution define a family of transmembrane AMPA receptor regulatory proteins. J Cell Biol 161:805-816. CrossRef Medline

Tomita S, Adesnik H, Sekiguchi M, Zhang W, Wada K, Howe JR, Nicoll RA, Bredt DS (2005) Stargazin modulates AMPA receptor gating and trafficking by distinct domains. Nature 435:1052-1058. CrossRef Medline

Trigo FF, Chat M, Marty A (2007) Enhancement of GABA release through endogenous activation of axonal $\mathrm{GABA}_{\mathrm{A}}$ receptors in juvenile cerebellum. J Neurosci 27:12452-12463. CrossRef Medline

Trigo FF, Bouhours B, Rostaing P, Papageorgiou G, Corrie JE, Triller A, Ogden D, Marty A (2010) Presynaptic miniature GABAergic currents in developing interneurons. Neuron 66:235-247. CrossRef Medline

Turecek R, Trussell LO (2001) Presynaptic glycine receptors enhance transmitter release at a mammalian central synapse. Nature 411:587-590. CrossRef Medline

Turecek R, Trussell LO (2002) Reciprocal developmental regulation of presynaptic ionotropic receptors. Proc Natl Acad Sci U S A 99:13884-13889. CrossRef Medline

Turetsky D, Garringer E, Patneau DK (2005) Stargazin modulates native AMPA receptor functional properties by two distinct mechanisms. J Neurosci 25:7438-7448. CrossRef Medline

von Engelhardt J, Mack V, Sprengel R, Kavenstock N, Li KW, Stern-Bach Y, Smit AB, Seeburg PH, Monyer H (2010) CKAMP44: a brain-specific protein attenuating short-term synaptic plasticity in the dentate gyrus. Science 327:1518-1522. CrossRef Medline

Vorobjev VS (1991) Vibrodissociation of sliced mammalian nervous tissue. J Neurosci Methods 38:145-150. CrossRef Medline

Wadiche JI, Jahr CE (2001) Multivesicular release at climbing fiberPurkinje cell synapses. Neuron 32:301-313. CrossRef Medline

Wang PY, Petralia RS, Wang YX, Wenthold RJ, Brenowitz SD (2011) Functional NMDA receptors at axonal growth cones of young hippocampal neurons. J Neurosci 31:9289-9297. CrossRef Medline

Wang Y, Small DL, Stanimirovic DB, Morley P, Durkin JP (1997) AMPA receptor-mediated regulation of a Gi-protein in cortical neurons. Nature 389:502-504. CrossRef Medline

Wilson RI, Nicoll RA (2001) Endogenous cannabinoids mediate retrograde signalling at hippocampal synapses. Nature 410:588-592. CrossRef Medline

Yamazaki M, Ohno-Shosaku T, Fukaya M, Kano M, Watanabe M, Sakimura K (2004) A novel action of stargazin as an enhancer of AMPA receptor activity. Neurosci Res 50:369-374. CrossRef Medline

Zhang SJ, Jackson MB (1995) GABA $_{\mathrm{A}}$ receptor activation and the excitability of nerve terminals in the rat posterior pituitary. J Physiol 483:583-595. Medline

Zhang W, St-Gelais F, Grabner CP, Trinidad JC, Sumioka A, MorimotoTomita M, Kim KS, Straub C, Burlingame AL, Howe JR, Tomita S (2009) A transmembrane accessory subunit that modulates kainate-type glutamate receptors. Neuron 61:385-396. CrossRef Medline

Zhang Y, Mori M, Burgess DL, Noebels JL (2002) Mutations in highvoltage-zctivated calcium channel genes stimulate low-voltage-activated currents in mouse thalamic relay neurons. J Neurosci 22:6362-6371. Medline 